\title{
Assessment of The Socioeconomic and Environmental siderations In Designing Disaster Risk Preparedness Measures at Wilson Airport, Kenya
}

\author{
Paul Muthee Kanyi Dr.Peter K. Kamau,Prof.Caleb Mireri. \\ Department of Environmental Planning and Management.School of Environmental Studies, Kenyatta University \\ , Nairobi, Kenya Correspondence: Professor Caleb Mireri
}

\begin{abstract}
The aviation sector is one of the most important sectors for any country especially its ability to promote interconnectedness within countries as well as between countries. However, the sector faces many risks caused by various emergencies and accidents associated with the sector, and much so in the precincts of airports. The impact of these accidents causes monumental social, economic and environmental consequences to victims. The exponential growth of the sector in the country calls for special attention by relevant stakeholders to devise strategies to address disaster preparedness issues. This is especially due to the fact that the country has already experienced a number of aviation disasters and mishaps related to the industry. Consequently, this study sought to assess the appropriateness and adequacy of the existing physical infrastructure in mitigating aviation risks in the airport. This study was carried out at Wilson airport located in Nairobi West. The qualitative design was applied in this study to analyze and describe the effects of land use changes on airport and flight safety in a rapidly growing aviation sector. The target population for the study comprised of 50 aviation regulators, 50 air operators, 100 service providers and communities living around the Airport. Primary data was collected by use of questionnaires, interview guide and Focused Group Discussions while Secondary data were collected from written or published records and maps from the Kenya National Bureau of statistics. Quantitative data was analysed by use of descriptive statistics such as frequencies and percentages while qualitative data was analysed using content analysis. The study found that $37(65 \%)$ of respondents indicated that the location of Wilson Airport is a threat, while $20(35 \%)$ of the respondents indicated that the location of Wilson Airport is not a threat to the security and safety of the airport. Regarding the effect of environmental factors on the safety of Wilson Airport, the study found that $51(89.5 \%)$ of respondents indicated that the location of the airport near tourist attraction sites such as Uhuru Gardens negatively affects the safety and security of the airport to a very large extent. Other environmental factors included: the presence of tall structures, visual obstructions, and land uses that attract wildlife in or near the runway approach and departure areas. Thus, socio-economic and environmental consideration is a determinant of disaster risk preparedness at Wilson Airport
\end{abstract}

Key Words:Aviation risks, physical infrastructure, preparedness

\section{INTRODUCTION}

An airport incident can occur anywhere, at any time - day or night, under any weather condition, and varying degrees of magnitude; it can occur instantly or develop slowly; it can last only a few minutes or go on for days (United States Department of Transport, 2009). It can be natural, such as a hurricane or earthquake, or it can be 'man-made', such as a hazardous materials spill, civil unrest, terrorism, and major fire or power outage. Moreover, emergencies of the same type can differ widely in severity, depending on degree of warning, duration, and scope of impact (United States Department of Transport, 2009).

An airport incident can occur anywhere, at any time - day or night, under any weather condition, and varying degrees of magnitude; it can occur instantly or develop slowly; it can last only a few minutes or go on for days (United States Department of Transport, 2009). It can be natural, such as a hurricane or earthquake, or it can be 'man-made', such as a hazardous materials spill, civil unrest, terrorism, and major fire or power outage. Moreover, emergencies of the same type can differ widely in severity, depending on degree of warning, duration, and scope of impact (United States Department of Transport, 2009).

According to Gooch (2007), airport aviation increases the economy of a nation by providing employment globally. For instance in Canada, the airport industry generates $\$ 8$ billion dollars and provides 150,000 job opportunities annually. The International Civil Aviation Organization (2006) noted that 2.1 billion passengers travelled by flight globally. This has great influence on global markets. Airport aviation improves global socio-economic development. However, there is growing concern over increasing aviation-related 
disasters globally. Most of these disasters occur when aviation and related businesses around airports are increasing thus posing enormous risk and dangers to the immediate precincts as well as to adjoining airports. Though aviation disasters occur worldwide, there is special concern for aviation disasters in Africa (Kwiatkowski, 2001). The potential for disaster exists everywhere, and there is resultant devastating cost: suffering and loss of life and. Emergencies are perceived as low probability events and preparedness requires time and finances. This often results in planning needs being overlooked. Lack of planning can cost airports and communities a high price including: health and safety problems, social disruption, lawsuits, negative publicity, liability, post-emergency psychological effects. While every contingency cannot be anticipated and prepared for, a strong emergency preparedness programme can limit negative these impacts.

Dannat (2002), observes that air transport has remained one of the most regulated and restrictive industries in international trade. Domestic deregulation and liberalization progress at an uneven pace and liberalization of the international markets has yet to overcome numerous obstacles. Air carriers therefore need to build extensive global networks to realize economies, scope and density and meet consumer demands. The need for expansion and the increase in consumer demand therefore brings the global aviation industry into perspective.In the last two decades, Kenya has witnessed a number of fatal aviation disasters including the Busia (24th January 2003), Marsabit (10th April 2006), Narok (14th June 2008) and Ngong plane (10th June 2012) disasters in which prominent Kenyan political, administration and civil servant leaders have lost their lives (Mutugi and Maingi, 2011: 40). Reports on inquiries into these disasters have pointed to poor aviation environments and non-compliance with international aviation standards and regulations (Mokaya and Nyaga, 2009). Separately, a report by the Aviation Safety Networks (ASN, 2010), provides data of several aviation accidents that have occurred in Kenya between the years 2006 and 2009. The report further observes that it is evident that $50 \%$ of the air accidents occurred during take-offs, $28.6 \%$ during landing and $21.4 \%$ during cruise. Take-offs and landings accounted for $78.6 \%$ of the accidents. This is despite the fact that Kenya is a signatory to the International Civil Aviation Convention (ICAC) that sets the standards and regulations to which airports and aerodromes must conform (Mokaya and Nyaga, 2009).

Suda (2000) states that the development of airfields and airports in Kenya requires terrain that is level and free of artificial obstructions in the vicinity. This is similar to other global scenarios. As a result of these factors, airports have tended to develop on large flat sites and affect their social environment and vice versa. Airports originally constructed far from town are becoming embedded in metropolitan areas that grow around them. People live and work much closer to the airport fence than airport and city planners anticipated.

The Kenya Association of Air Operators (KAAO) has constantly warned that airports such as Wilson Airport pose real danger to aviation security and safety due to encroachment onto airport space by residential and commercial buildings, which ultimately renders flight paths invisible to pilots and inhibits smooth take-off and landing. Wilson Airport is currently facing an acute problem of encroachment onto its flight path by exponential real estate developments. Considering it is an airport with approximately 120,000 landings and take-offs annually, as reported by the Kenya Civil Aviation Authority (KCAA, 2007), these encroachments pose a real risk on safety. Despite the increase in threats to aviation safety challenges in Kenya, the KCCA, in response to the national developmental goals envisioned in the Kenya Vision 2030, has put in place measures to ensure Kenyan air operations meet international safety and security requirements to meet the international standards including: infrastructural facilities, communication facilities, and security checks (Hudson, 1997). To achieve this, the Authority needs to augment its capacity to deliver quality regulatory oversight services and ensure its compliance to civil aviation regulations (Kenya Vision 2030 Blueprint, 2009).

Africa's aviation disaster record, and the question marks raised especially by key stakeholders in the aviation industry such as KAA, Association of Air Operators and KCAA concerning compliance to aviation standards and regulations in Kenya, presents researchers and scholars an opportunity to examine these issues in a detailed and systematic way to help reverse the negative aviation record in Kenya and Africa (Oladele, 2005). This study examined the Kenyan aviation disaster risk preparedness context with and recommends means to mitigate disaster occurrence and enhance disaster risk preparedness. It also adds value to aviation studies in the country.

\subsection{History of Wilson Airport}

The history of Wilson Airport (WAP) dates back to the First World War. Commercial routes were pioneered by Imperial Airways and its successor British Overseas Airways Corporation (BOAC) in the 1920's. In July 1929, Wilson Airways Ltd was formed by Mrs. Florrie Wilson to operate from an airfield in Dagoretti Corner, Nairobi. Later, the airport was relocated to the present site of Wilson Airpor and originally called Nairobi Aerodrome. The construction work was carried out by the Public Works Department. By 1933 two murram (non-tarmac) runways had been laid. The Imperial Airways then commenced operation of an airmail service to Kisumu in July that the same year (http://www.kaa.go.ke/airports/wilson). 
In 1962, the GoK renamed the aerodrome 'Wilson Airport' to honour its founder. Today the airport has expanded to become a major domestic airport, a gazetted border control point accommodating short-haul scheduled domestic flights and services, international, and private and charter flights. Wilson Airport is situated at latitude 0118 's and longitude $3648^{\prime} 49^{\prime \prime} \mathrm{E}, 5 \mathrm{~km}$ from the Nairobi city centre, and borders Nairobi National Park to the immediate south. It is ICAO Class 2, Category 5, and holds the code HKNW. Currently, Wilson Airport is one of the busiest airports in terms of aircraft movement in East and Central Africa. Domestic flights constitute $90 \%$ of the total flights from the airport with international flights accounting for $10 \%$. The airport is a fast and convenient gateway from Nairobi into Kenya's magical interior. Destinations served from the airport include Maasai Mara, Mombasa, Amboseli, Lamu, Diani, Lokichogio, Nanyuki and Kilimanjaro. It is also a modern hub of general aviation in East and Central Africa (https://www.kaa.go.ke/airports/wilson).

\subsection{Problem statement}

Wilson Airport Nairobi is the smallest of the two civil aviation facilities in the city. The airport, which is used mostly by general aviation traffic, caters for both international and domestic traffic. The facility is mainly used by tourism, agriculture and health sectors of the economy. Wilson Airport handles about 120,000 landings and take-offs every year, most of it local and regional traffic. As a result of faster check-in times and fewer flight delays, as compared to Nairobi International Airport, Wilson Airport is commonly used by business executive aircraft for both domestic and International travel. Common domestic destinations from Wilson Airport include Kisumu Airport, Mombasa International Airport and Eldoret International Airport.

Despite existence of comprehensive policies on aviation safety in Kenya, critical aviation safety challenges continue to emerge in the existing airports. Over the past decade, Wilson airport has faced different challenges ranging from constrained spaces and aviation related accidents. The airport is constrained by expansion and development space largely due to expansion of aviation businesses as well as developments in its adjoining neighbouring areas. Among the many security and safety concerns raised have been encroachment into airport space with claims that illegal structures and numerous other high-risk business developments within and around the airport have significantly affected flight safety in the airport. All these increasing infrastructural developments pose a threat to aviation activities at the airport.

Different studies have been done on airports in Kenya. Mukaria (2013) did a study on knowledge, awareness and conformity to International Airport emergency preparedness standards: the case of Wilson Airport in Nairobi, Kenya. The study found that dissemination of information among stakeholders was average resulting into low cooperation in the cases of emergency at the Wilson Airport. Obwaya (2010) did a study on disaster risk reduction strategies in preparedness at Jomo Kenyatta International Airport (JKIA) Nairobi Kenya. He found that JKIA plans, facilities and personnel cannot handle a large-scale disaster. No study has been done on the effects on land use changes on airport safety in Kenya. This study therefore examined thesocioeconomic and environmental considerations in designing disaster risk preparedness measures at Wilson airport, Kenya.

\section{LITERATURE REVIEW}

This section presents theoretical and empirical review

\subsection{Chaos Theory}

One counter to the linearity of the lifecycle approach was to explore whether Chaos Theory which emphasizes multi-directional causality and lack of predictability has utility for understanding crisis management. Chaos theory is built on the two ideas hat systems, no matter how complex, rely on an underlying order, and that within such systems very small changes or events can cause very complex behaviors or outcomes.

Recognition of this non-linear interaction between components prompted Priscilla Murphy (1996) and later Matthew Seeger (2002) to advance the application of chaos theory to crisis management. Chaos theory suggests that it is impossible to detect simple linear cause and effect relationships. Instead, there are many variables that interact in convoluted ways to produce disaster. Chaos theory would thus recommend that vulnerability be reduced by addressing multiple variables simultaneously. The theory of chaos stresses that the world does not necessarily work as a linear relationship with perfectly defined or with direct relations in terms of expected proportions between causes and effects. The chaos occurs when a system is very sensitive to the initial conditions. These initial conditions are the measured values for a given initial time. The presence of chaotic systems in nature seems to place a limit on our ability to apply physical deterministic laws to predict movements with any degree of certainty. Indeed, one of the most interesting subjects in the study of chaotic systems is the question of whether the presence of chaos may or may not produce ordered structures and patterns on a wider scale. In the past, the dynamic systems showed up completely unpredictable and the only ones who could aspire to be understood were those that were represented by linear relationships, which are not 
the rule. On the contrary, there are some situations clearly isolated.Chaos theory was used to explain how response to disasters may compromise its management. Focusing on how the airport is prepared to prevent and handle disaster cases, the theory helped in explaining how any disasters and disconnect in handling disasters would compromise disaster management.

\subsection{Socio-economic and Environmental considerations in Disaster Risk Preparedness of Airports}

Today, disaster risk preparedness includes hazards such as: extreme weather, hazardous materials, accidents, natural disasters, and acts of terrorism. According to Stambaugh (2009), public and private sectors have invested heavily in improving threat assessments, plans, training, resource sharing, communications and stockpiles of critical supplies.No airport has sufficient resources to unilaterally respond to an emergency situation. Each airport must depend to some degree on resources from its surrounding communities to deal with an emergency. According to Ayres (2009), preparation is crucial if an airport is to respond quickly, efficiently and effectively to an emergency. While every contingency cannot be anticipated and prepared for, a strong emergency preparedness programme limits negative impacts of emergencies including liability and postemergency problems. The following sub-sections of this study deal with different aspects of disaster risk preparedness including: causes of aircraft disasters, disaster management, and airport hazards. This study sought to find out the sufficiency and efficiency of the resources and facilities at Wilson Airport and how they affect its preparedness for disasters.

\subsubsection{Causes of aircraft disasters}

Travel by air is, by and large, perceived as a very safe mode of transport based on the nature of flying and the sheer volume of air travel. However, accidents in air travel are on the rise. Aircraft disasters have a multiplicity of causes and effects. Planes are flying at such high speeds and are so massive that any accident is almost sure to cause serious injury or death to the passengers. Airplanes also fly over dangerous areas, like oceans or mountains, hence reducing the chances of surviving an accident. There are various causes of aircraft accidents, some of which cannot be controlled. However, many accidents result from human error and can be avoided. According to Devine (2009), some of the causes of aircraft accidents include structural defects, tower error, pilot error and bad weather.

\section{Pilot error}

Human error, by a pilot, maintenance engineer, ground crew member, manager or supervisor, designer or someone involved in the manufacture of an aircraft, causes a majority of aircraft accidents. Airplane accidents may also arise from faulty aircraft construction or maintenance, incorrect instructions to aircrew, mistakes in re-fuelling or securing the aircraft doors, overloading and excessive stress of staff. In the air, pilots may make navigation errors or choose to fly in cloudy conditions using visual cues such as landmarks instead of computerized navigation instruments (Swabrick, 2009).

Approximately $80 \%$ of all aircraft accidents occur shortly before or during take-off and landing. These are usually said to have been caused by "pilot error", although these days this is more often referred to as "human error", to emphasize that pilots are simply human beings. Pilots must safeguard passengers and the aircraft. Pilot error is assessed first any time an airplane crashes.

Human beings make mistakes therefore human error must therefore be assessed in occupational accidents, including $70 \%$ to $80 \%$ of those in civil and military aviation. While the number of accidents attributable solely to mechanical failure has decreased markedly over the past 40 years, those attributable to human error have declined at a slower rate (Krasner, 2009).

Pilots are particularly susceptible to perceptual errors when their sensory input is degraded for example at night or in visually impoverished environments. Aircrew runs the risk of misjudging distances, altitude, and descent rates, and of responding incorrectly to what they see. There are times when human error, particularly by pilots and air traffic controllers, has led aircraft to miss runways, and to crash into buildings and other planes, resulting in fire outbreaks.

According to the United States of America National Transport Safety Board (2003), out of 40 aircraft accidents at or near Hayward Airport since 1983, 17 were the result of human error. Human error includes actions of inexperienced pilots (students), veering off the runway, failure to follow instructions from air traffic controllers, incidents brought about by an impaired mental state of the pilots, misjudging of weather, and loss of control of the aircraft by the pilots (although the latter is not always caused by human error). Indeed, human error and inexperienced pilots have especially played a big role in aircraft accidents (National Transport Safety Board $\{$ NTSB $\}, 2003)$. 


\section{STRUCTURAL DEFECTS}

Structural defects can lead to dramatic and unpredictable aviation accidents. Defects can range from faulty or aging wires, to corrosion, and fuselage loss. In 1988, a Boeing 737 flown by Aloha Airlines experienced a ruptured fuselage, tearing part of the cabin apart and blowing a flight attendant hurtling out of the plane to her death. The accident was caused by problems with the adhesive bonding process; a problem Boeing was already aware of (Devine, 2009). Plate 1 shows Aloha aircraft accident wreckage.

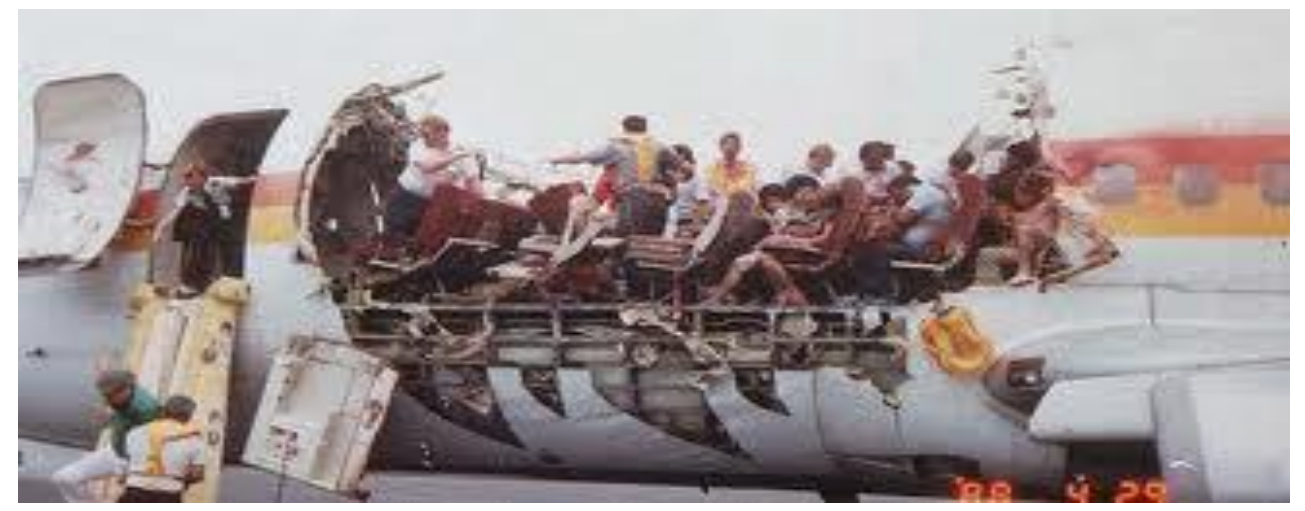

Plate 1: Aloha aircraft accident, Honolulu 1988 (NTSB, 1990)

Structural problems in aircraft are usually related to corrosion, surface cracks, fatigue cracks, and skin disbonds. Aging aircraft may experience structural defects from general use and lack of maintenance. When these problems go undetected, the lives of passengers and flight crew are endangered, especially because of the precise calculations and physics of flying. It is a complicated science, and a bad design can be problematic. Equipment must be maintained and checked regularly to reduce the chance of mechanical failure (Devine, 2009).The International Civil Aviation Organization (ICAO) has strict guidelines governing how often these inspections have to be made. Engine failures have caused a number of accidents and the United States of America National Transport Safety Board (2003) records that out of the 40 air accidents at or near Hayward Airport since 1983, 12 were the result of internal aircraft problems, including engine failure and fuel leaks. Other internal problems include power and gear failure, which have led to crash landings, sometimes resulting in loss of life and property.

Engine failure is a mechanical problem that can lead to aviation accidents. Such failure may arise from insufficient fuel and engine parts breaking off. Pilots and crew are specially trained to manage engine failure as best they can by gliding the plane to a safe landing, but aviation accidents resulting from this mechanical problem can sometimes be horrific (Devine, 2009).

\section{NON-COMPLIANCE WITH REGULATIONS}

The International Civil Aviation Organization (ICAO) and member states including Kenya (under Kenya Civil Aviation Authority (KCAA) has very specific rules that cover almost all aspects of air travel including: equipment, ground personnel, passengers, luggage security, pilots, and airports. The rules are designed for the safety of all travelers and flouting them can result in dangerous situations (ICAO, 2004).

\section{TOWER ERROR}

Air traffic controllers must make sure that planes and pilots do not endanger each other. Pilots are dependent on these controllers to give timely, accurate information on weather, landing patterns, and runway positions, among other things. Collisions can occur if this information is not accurate and prompt (Kumar and Malik, 2003).Recent reports of air traffic controllers acting dangerously only only highlight the adverse consequences that can arise from their actions. By August, 2005, 200 human-related errors had been made by New York air traffic controllers, compared to 24 for all of 2004. Mistakes and lapses in vigilance by these controllers can result in aviation accidents and loss of life (Krasner, 2009).

\section{BAD WEATHER}

Bad weather causes a third of aircraft accidents, and most of air traffic delays, which costs airlines four billion dollars annually. Thunderstorms present the worst hazards to aircraft. A single thunderstorm contains multiple threats to aircraft including: heavy precipitation, hail, lightning, very severe turbulence, low-level wind shear, microburst, and icy conditions. Wind, mist, and fog, particularly with regard to light aircraft, that impair 
visibility and air pressure, have been noted to lead to air crashes. According to Baum (2010), failing to heed upto-date weather forecasts is unwise especially when the elements are particularly changeable and intense due to mountainous terrain, and strong winds and turbulence.Severe weather can test the structural strength of aircraft designed for less rigorous conditions and the skill of the pilots (Swabrick, 2009). Although poor weather conditions are beyond the control of pilots, airlines and flight crew, these people are responsible for the safety of their passengers. When the decision is made to go ahead with a flight disregarding weather advisories, lives are put at risk.

\section{AIRPORT HAZARDS}

Hazard identification considers potential sources of system failure, including that of equipment. Other sources of such failure are the airport operating environment, and inadequate operational and maintenance procedures. According to Ayres (2009), organizational and human factors include all persons having access to the workplace (e.g. airport workers, passengers, contractors, delivery personnel as well as airport employees) and the hazards and risks arising from their activities, the required skills and training to perform procedures, and their varying behaviour, medical conditions and physical limitations. Other factors include hazards arising from the use of equipment or services supplied to the airport and its tenants; operational practices and procedures, where regulatory factors, including the applicability and enforceability of regulations; certification of equipment, personnel and procedures is not observed; and the adequacy of the oversight body is questionable (Devine, 2009).All hazards including terrorist attacks, mid-air collisions, and bird hazards, and others that can contribute to an aviation accident must be seriously considered to save the lives of passengers and innocent people. Over the last two decades, around 800 cases annually of birds slamming into a UK-registered civil aircraft were reported to the CAA. Since November 2004 when legislation was put in place mandating pilots to report bird strikes, double the number have been noted. This confirmed that there had been a problem of underreporting such incidences. Most bird strikes affect certain aircraft types, standard aerodrome activities; and modest numbers of the species that commonly frequent airfields. The consequences are catastrophic because birds were ingested into engines resulting in engines losing power and pilots losing control of the aircraft. Even single, relatively small birds (American kestrel, Woodpigeon, and Lapwing for example) can cause accidents (Bird Hazard Risk Assessment, 2013).

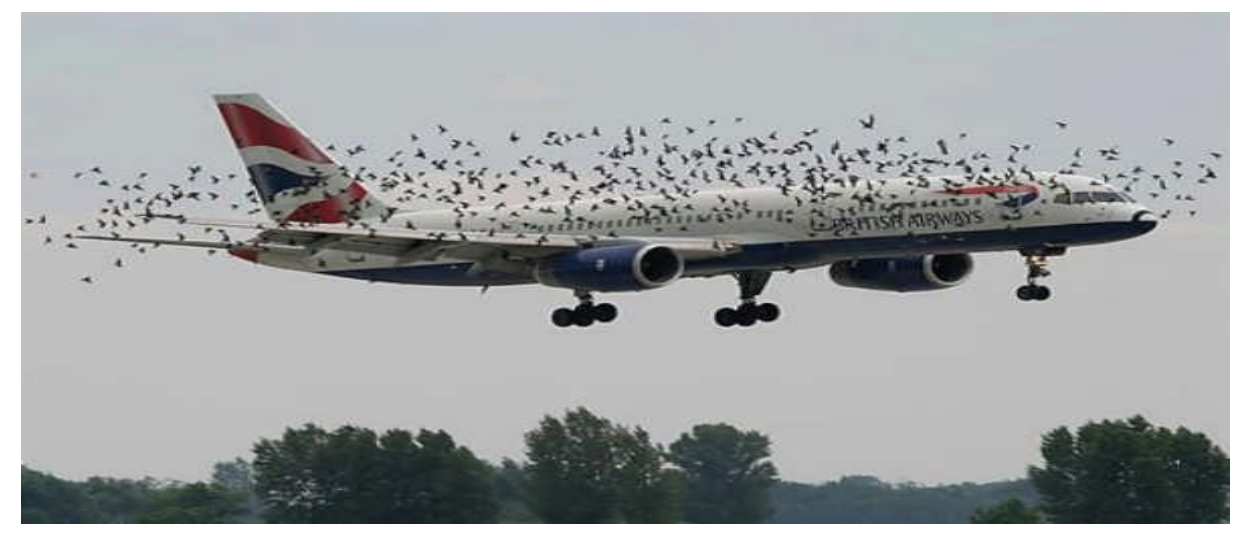

Bird Hazard Risk Assessment (2013), North West Bird Control Plate 2 Flying through a Swarm of Birds

Aircraft collisions with birds (bird strikes) are an increasingly serious economic and safety problem. Allan and Orosz (2001) estimated that aircraft accidents that result from bird strikes cost commercial air carriers over $\$ 1.2$ billion worldwide annually. At least 192 people died and 140 aircraft were destroyed in civil and military aircraft from 1988-2004 worldwide from such strikes (Richardson and West, 2000; Thorpe, 2003).

Bird strikes that cause these accidents have increased because of increasing bird populations. Highly successful programmes funded by governmental organizations, such as: pesticide regulation, expansion of wildlife refuge systems, wetlands restoration, and land use changes resulted in dramatic increases in populations of wildlife species in North America (Dolbeer, 2000) and Europe (Buurma, 1996; Allan and Feare, 1996). For example, 24 of the 36 largest $(>1.8 \mathrm{~kg}$ ) bird species in North America have shown significant population increases over the past years and only 3 species have shown declines (Dolbeer and Eschenfelder, 2003).

Exacerbating this problem is the fact that these large birds exceed the size standards under which large commercial aircraft components and engines are certified (MacKinnon et al., 2001). Furthermore, many bird species now live in urban environments, including airports. The quieter engines of airplanes today render it 
difficult for birds to detect their approach and avoid striking into them. The older and noisier aircraft were easier to detect as they approached, and therefore to avoid, which limited the bird strikes (Burger, 1983; Kelly et al., 2001). To address this problem internationally, the 188 member states of the International Civil Aviation Organization (ICAO) ratified the Convention on Civil International Aviation in 1990, which outlined three recommended practices regarding hazards to aviation caused by birds including that authorities: (i) assess the extent of the hazard posed by birds on or in the vicinity of airports, (ii) take necessary action to decrease the number of birds by adopting measures for discouraging their presence, and (iii) eliminate or prevent the establishment of any site in the vicinity of the airport, which attract birds and endanger aviation.

On November 27, 2003, because of the increased concern regarding bird hazards to aviation, ICAO member states changed these Recommended Practices into ICAO Standards. The Standards establish requirements which authorities operating international airports must comply with to manage bird hazards to aviation (Dolbeer and Eschenfelder, 2004). In addition, ICAO made the reporting by pilots of bird strikes a Recommended Practice.

In South Africa, the aviation industry has grown tremendously during the past years, and this has also led to increase in bird strike risk. Bird strikes are as common a problem in South Africa as elsewhere in the world. Analysis of bird strike information indicates that significant bird strike risk exists at some South African airports, but measures to manage the problem have been inadequate. Short-term assessments (Pienaar and Greyling, 1990; Anderson and Kok, 1991; Rasmussen, 1992; Grote, 1994) provided recommendations, but these were often only implemented for a short while.Bird strikes, as in other parts of the world, are a serious problem in Kenya. Lack of reporting and data collation precludes up-to-date documentation on the situation. Over the past 17 years (1984-2000), Kenya Airways has suffered 187 bird strikes within Kenya and 64 of these were with identified species (Archer, 2001).

While most bird strikes involving Kenya Airways are by resident species, the majority of strikes are thought to be by the black kite migrant subspecies. From 1999 to 2000 alone, Kenya Airways incurred costs of approximately $\$ 5.3$ million, of which $\$ 2.9$ million was attributed to two collisions with Marabou Storks (Archer, 2001).The Kenya National Bird Strike Committee (KNBSC) has for several years identified the presence of water bodies and garbage in the vicinity of airports as the main bird attractants. However, these observations have not been taken into consideration when new airports are constructed. Moreover, the local councils responsible for urban planning and managing solid waste have not been involved in air safety development or planning, for example at the Eldoret and Kisumu airports. Fish processing and selling activities attract birds and threaten the safety of airplanes at Kisumu Airport, and Eldoret Airport also has wall features and roofing that attracts nesting birds, especially since it is built near a wetland that has resident grey-crowned cranes residing near the runway. These Cranes are low fliers and threaten the safety of airplanes on take-off. The airlines, Kenya Airports Authority (KAA) and the Directorate of Civil Aviation (DCA) would like both the cranes and the wetland extirpated. The solution to this issue is complex since the wetland is on private land and had its resident crane population even before the airport was built. Eldoret Airport is an important structure in the development of western Kenya, but ensuring the safety of aircraft from the grey-crowned cranes continues to be a challenge for airport authorities.

Jomo Kenyatta International Airport (JKIA), Wilson Airport and Kenya Air Force Base in Nairobi are all threatened by the presence of an increasing number of scavenging birds that feed of the increasing garbage in the vicinity, especially Marabou Storks. The Nairobi City Council (NCC) now intends to move Nairobi's biggest garbage dump from a site in Dandora to Ruai, in Nairobi. The Dandora garbage dump is approximately $6.5 \mathrm{~km}$ north-east of JKIA, with a resident population of approximately 5,000 Marabou Storks attracted to the garbage. Ruai is about seven kilometres from the end of the JKIA runway. The movement of the dump from Dandora to Ruai will increase the number of such birds near the airports and the resultant bird strikes. JKIA is East Africa's busiest airport, hosting 34 airlines and handling over 3 million passengers annually. NCC has not considered the dangers of designating garbage-dumping sites near airports. The Kenya National Bird Strike Committee (KNBSC) has now incorporated the NCC within its membership and both are working to find a solution to this problem.

Airplanes landing or taking off from airports in Mombasa and Malindi along the Kenyan coast are threatened by bird strikes from scavengers. Refuse and garbage dumps from populated areas in their proximity attract these Birds. The Indian House Crow (Corvus splendens) is most prevalent in this area. Efforts to move garbage to sites away from airports are underway. A programme to reduce Indian House Crows along the Kenyan coast is ongoing and has proven successful (Jackson 2001).

Human beings create disasters especially with the increase in inventions of science and technology (KiemaNgunnzi, 2002). Aviation travel is one such invention, which is unique among other transportation models because aviation accidents, even relatively minor ones, can result in mass fatalities due to the unique nature of the aviation environment. 
According to Krasner (2009), when automobiles collide, trains derail or ships sink, passengers may face the triple threat of blunt trauma, and harm from fire and smoke. However, these accidents do not happen suddenly as is the case when an aircraft crashes when flying at approximately $150 \mathrm{mph}$ (Devine, 2009).

Essentially, a commercial plane is like a crowded office building, occupied by as many as 600 people, but unlike the spacious high ceiling suites of a skyscraper, passengers are crowded into a tightly confined cabin space. Thus even a small fire in one end of the cabin will produce blinding, toxic smoke that will overwhelm every passenger almost instantly. According to Ayres (2009) and Swabrick (2009), in the ensuing panic, passengers try to navigate the tight confines of a narrow aisle to reach emergency exits.

The potential for airplane disaster has increased significantly in recent years as planes carry more passengers, and not equipped or staffed to handle increased traffic. The airports are also ill-equipped to respond to aviation accidents because they have inadequate facilities to handle many travellers (Cleary and Dickey, 2010).Aircraft accidents do not have to spell doom for the occupants. The Federal Aviation Agency (FAA) asserts that airports with well thought-out disaster plans and adequate rescue capacities have always averted disasters. A survey of airport emergency services conducted by the International Association of Fire-fighters in 1998, found that existing FAA regulations are often ignored when it comes to passenger safety. For example, FAA requires airports to suspend air operations when fire protection falls below minimum levels, in extinguishing agents, staffing levels, and medical emergency staff. Only two airports were found to comply with these regulations worldwide, namely Manchester Airport and JFK Airport, New York (ICAO, 2004).

According to Swabrick (2009), except in a catastrophic incident when a plane explodes or slams into the earth, most accidents are survivable because the vast majority occurs at or near airports during take-off and landing. Although take-off, initial climb, approach, and landings account for 18\% of flight times, it is during such times that $79.9 \%$ of all aircraft accidents take place. The National Transport Safety Board (NTSB) classifies fatalities in three categories: during the impact, post impact, and at undeterminable times. Excluding the latter, $78 \%$ of fatalities occur from smoke inhalation and burns after the impact and during the climb or descent, resulting (Owen, 2003). Thus, a focus on airport disaster risk preparedness zeroes in on the most crucial zone of aviation safety: take-offs and landing.

Take-offs and landings place passengers and crew in circumstances most vulnerable to accidents. Kenya's Wilson Airport is reputed to be the busiest in Africa with approximately 500 local flights per day (Mirichu, 2004). The airport is geared more towards cargo freight than human transport. It transports 1,000 passengers daily, while Jomo Kenyatta International Airport handles 20 international flights per day $(10,000$ passengers daily). JKIA is reported to have handled 3.2 million passengers in 2003 (Mirichu, 2004). A major airplane crash therefore exacts a heavy emotional and monetary toll on society, and the human cost to victims, survivors, and their families is immeasurable. The direct cost of just one fatal commercial air crash can total hundreds of millions of dollars.

When an airplane crashes and the airport fire-fighters can reach the victims a few minutes thereafter, the survival rate is $100 \%$. Unfortunately, most airports do not respond that quickly because they lack the necessary firefighting personnel and equipment. This places the lives of passengers, airport staff, and firefighters in jeopardy, and with more than 350 million people including crew flying in and out of the world's airports each year, the potential for disaster is even greater (Ayres, 2009).

In cases where airlines have been associated with frequent air disasters, client exodus is expected and this leads to loss of revenue. Compensation claims for disaster victims are often high and reduces airline' profits; there is also the loss incurred as a result of the damaged aircraft, and property (Kiema-Ngunnzi, 2002).

Air disaster can disrupt telephone communication which is critical for coordinating emergency rescue operations, so the task of controlling curious crowds that normally gather in a disaster scene is hampered. This leads to psychological and physical effects on the victims, friends, close relatives, and even onlookers. Victims of the 1998 Nairobi bomb blast continue to live with post-traumatic stress disorder; e they have lost their confidence, and live with perpetual fear of another bomb blast (Kiema-Ngunnzi, 2002). These reactions are similar to the effects of air crash disasters.

The East African (2004) accuses the Kenya Airports Authority (KAA), which regulates Kenyan airports, of many ills, including inefficiency, irregularities and unethical practices in its operations, especially regarding a Busia, Kenya, plane crash that took place in 2003. The newspaper report says that adequate security is required at Kenyan airports and their respective perimeter fences to reduce the risk of terrorist threats, as well as smuggling and illegal immigration. Training in fire-fighting, air traffic control and inspectorate departments was also reported as lacking. There is therefore the need to look more closely at the above weaknesses with reference to Kenya's premier airport. 


\section{BIRD CONTROL METHODS}

Generally, successful bird control methods at airports vary with location, species, bird behaviour, season, climate, circumstance etc. As a result, airports have a bird control programme that is based on local experience and situation (Stenman, 1990). Bird hazards may also change with varying land use (Godsey, 1997). In literature sources, bird control methods are divided according to: ecological and technical methods, active and passive methods or habitat management, chasing and elimination (Kuyk, 1981). Not all classifications offer a clear distinction between control methods; in fact, some may be placed in more than one category. In this study, a comprehensive classification is used in which three main perspectives in bird control at airports are distinguished: habitat modification, resource protection, and population management. Habitat modification means creating, adjusting, or altering the environment to make it less attractive to problem birds. Resource protection means making the area or resource unattractive or inaccessible to problem birds using exclusion, dispersal, and repellent techniques. Population management includes capturing, breeding control, and elimination methods (Cleary, 1994).

These methods deal with bird problems confined to the airport and its immediate vicinity, at lower altitudes (i.e. $0-300 \mathrm{~m}$ ), where the risks of bird strike are highest. These control techniques have remained relatively unchanged over the last 25 years (MacKinnon, 1996). A fourth and relatively new perspective in reducing the risk of bird strike is based on trying to predict the presence of birds on a larger scale, outside airports, and at higher altitudes. Predictive models are being developed, combining computer, radar and satellite technology, bird distribution data, and factors influencing migration patterns, such as season, geography and meteorology (MacKinnon, 1996). This is actually not considered bird control, because it does not affect the presence of birds.

\section{a) Habitat modification}

All birds need food, cover (shelter, safety, places to nest, rest and roost), and water to survive. The design and management of an airport's habitat eliminate or minimize such elements (especially hazardous species), reduces their population (National Wildlife Research Centre, 1999). Habitat modification should aim at problem species because it affects target birds and other bird species and animals. What is important is not to create circumstances that attract other species. Habitat modification is considered effective and prevents bird presence in an effective way. Measures should be based on ecological research of the airport area and its surroundings as every airport offers a unique situation. Continued and properly specialized maintenance of vegetation and water is important for success (Blokpoel, 1976).

\section{FOOD}

In urban, as well as rural areas, many food sources attract birds, especially gulls, pigeons and starlings. One bird finds the food and attracts others. It may act as a decoy to other birds or attract con-specifics by food calls (Kuyk, 1981). Rodents and insects also attract birds of prey or flocks of passerines (Klaver, 1999). If the attracted bird species is hazardous, control of the prey population is the solution. Food attractants often result from human activity. Examples of food attractants are: open water, trash bins, trash containers (especially when improperly handled), and worms on runways after rainfall, fishing vessels fish or meat industries, landfills, sewer treatment plants or lagoons, birds being fed in parks, grain storage, and agricultural activities. Awareness of such food sources at and around the airport is very important. Proper cleaning up, handlings of trash, supplemental bird control measures, and adjustment of land use are vital methods to prevent the attraction of birds (Godsey, 1997). Sewage lagoons or treatment plants and on-base landfills should be situated as far away from the runways as possible so that flights of attracted birds do not cross the aircraft paths. A small work surface, overnight waste dumping and immediate covering, combined with exclusion and repellent techniques are advisable to decrease bird attractants. High trees around landfills, dogs and continual harassment at landfills discourage gulls from feeding there (MacKinnon, 1997).

Insects and other invertebrates are an important food source for many species of birds. Gulls and Waders feed on worms that appear on runways during rain. Measures to reduce their number include: large scale sweeping of runways after rain, and repelling or killing worms in the grass strip along the runways with chemicals such as Benomyl and Thiodan (Endosulfan) (Blokpoel, 1976). Awareness of insect populations that are a food source increases by careful observation of bird species and their feeding behaviour. If necessary, insect control measures can be taken through or in combination with vegetation management. Chemical control through the use of Clorpyrifos for example, on crane flies (Tipulidae) is also useful. Agricultural land use attracts birds, depending on the type of crop and agricultural method used. Hay, cotton, and flax do not attract birds. Discouraging agricultural land use at Schiphol Airport resulted in significant decrease of birds around the airport (Klaver, 1999). 


\section{COVER}

Many habitats can be used by birds for cover or resting. At airports, such habitats are vegetated areas, such as fields, dunes (gulls, waders), shrub and trees (pigeons, passerines); bare areas, such as runways and other hard surfaces (gulls, waders), buildings (gulls, terns, pigeons, starling); and water bodies, such as lakes and ponds (gulls, waterfowl).Airports serve as relatively undisturbed areas for birds so when landscaping areas at airports, attention should be paid to bird-attracting aspects of the created habitats. Eliminating existing habitats or making them unattractive or inaccessible (exclusion) can solve many bird problems. Examples are: long grass management, prevention of seed or fruit-carrying plants, thinning trees at roost sites, draining wet and swampy areas, fencing of water bodies, and modifying buildings (Klaver, 1999).

Because most vegetation around airport consists of grass, long-grass management is a widely used and effective method to decrease the bird population. Whether long or short, grass is attractive to certain species. Short grass attracts the more hazardous bird species (mainly gulls, plovers, pigeons, and starling). Long grass management is generally considered the right approach in Europe (Blokpoel, 1976). Allowing the grass to grow to $15-20 \mathrm{~cm}$ height strongly diminishes the attraction to foraging or resting birds because the availability of food is less, there is no open view for predators, and flock integrity and communication are reduced. Mowing should start adjacent to runways moving towards the outermost grass areas (insect and other animals will move away from the runways) and should preferably coincide with periods of low flight activity. Long-grass management should be practiced up to 1 kilometre away from the runways (National Wildlife Research Centre, 1999).

The longer grass will attract more rodents than short grass, resulting in a higher number of raptors or herons. Also, some birds may find a more suitable place to breed (Pheasant, Grey Partridge). In general, these birds are less hazardous because they are more secretive, do not occur in large flocks, and fly less. Thus, an increase of these species does not diminish the positive effect of long grass management (Godsey, 1997).

Weeds and seed, or fruit-carrying plants (often pioneering on bare soils), limit grass growth and attract birds. To minimize these plants, specific herbicides or growth retardants may be used, and grass growth stimulated. Also, bare soil itself can be attractive as a feeding or resting site for birds. Planting grass on such areas and using fertilizers to stimulate grass growth is recommended (Godsey, 1997). Shrubs, trees and hedgerows at or nearby airports will attract birds and influence their numbers and movements. Currently, tree rows and wooded areas are used as noise and exhaust barriers, this may increase bird strike risk (Stenman, 1990). Trees and bushes provide food, shelter, and nesting opportunities. Attraction can be reduced by selecting plants and trees that do not produce fruit. Management should consist of thinning and pruning the trees to prevent the formation of roosting sites. Individual trees are frequently used as perches by raptors. Gradual transitions in vegetation, for example from grass via weeds and shrubs to trees, are attractive to birds.

Management should be aimed at keeping vegetation transitions abrupt (Godsey, 1997). High trees may make open areas and fields unattractive as a roosting site for gulls. Having tall trees airports however, is problematic but they can serve as roosting sites elsewhere (Kuyk, 1981). However, short grass can offer a safer situation, because of ducks and hawks nesting in long grass (Winnipeg, Canada) or hawks feeding on grasshopper in long grass (Mackay, Australia) (Blokpoel, 1976). In one case, a gull roost at an airport was successfully moved by making a site just outside the airport more attractive to the birds. Other practice examples of luring birds away by creating more attractive sites nearby do not exist.

\section{WATER}

Especially in coastal or arid sites, fresh water is very important to birds. Apart from (sewage) ponds, basins and canals, rain pools can also be attractive drinking and preening sites. They are also food sources as they contain amphibians, fish, and insects. Gulls and waterfowl in coastal areas show a strong preference for such locations (Kuyk, 1981). Gulls and other bird species often flock to temporary pools of fresh water at airports after heavy rains (Dolbeer, Belant and Clark, 1993). Standing (fresh) water at and around airports should be eliminated. Areas remaining wet after rain can be filled, leveled, and (re)planted with grass. If elimination is not possible, resource protection can also be a good solution. Drainage ditches should be deep (unattractive to waders and herons), and banks should either be steep (no shallow water) or graded (mowing up to the water possible) (Godsey, 1997). Vegetation, either emergent or submerged, should be removed (unattractive to wildfowl).

In periods of severe frost, salt water becomes an important attractant to some bird species if most of the fresh water inland has frozen over. Under such conditions, water birds (ducks, grebes, gulls) may move to coastal areas, resulting in increased movements (frost migration) and numbers (wintering flocks) of birds off the coast. Being a type of migration, this phenomenon cannot be counteracted by bird control measures. However, the circumstances leading to such movements are fairly predictable. 


\section{ZONING}

In conclusion, habitat management at airports and the surrounding environment is very important. Nearby land use practices that attract birds can reduce the effectiveness of airport control measures considerably (MacKinnon, 1997). Care should be taken in developing nearby reserves aimed at keeping birds, especially gulls and cormorants, away from the airport (Kuyk, 1981). Zoning regulations are common practice in most countries. At Schiphol Airport, there are three zones (indicated 1,2 and 3): the airport itself, 1 kilometre and 5, 5 kilometres around the runways. Within these zones, development of nature reserves or forest is unacceptable. Such regulations limit the possibilities for certain types of land use around the airport, such as landfills, agriculture, or nature refuges. Zoning prevents the build-up of hazardous wildlife populations near airports (MacKinnon, 1997).

\section{b) Resource protection}

Resource protection comprises all activities that make areas inaccessible or less attractive to birds. Apart from food, cover, and water, airports often offer relatively 'quiet' conditions, because there is little disturbance apart from engine noise. This is attractive to birds and can increase their number. Resource protection measures include 'passive' (e.g. wires across ponds, spikes on ledges) and 'active' (harassment with chemical, audio or visual means) methods, hereafter called exclusion and repellents, respectively (Cleary, 1994). The success of active harassment depends not only on the methods and bird species, but also on the shape the birds are in. When breeding, tired or hungry, gulls for example are harder to chase away. Also, the availability of alternative sites for birds in the vicinity determines the success (Kuyk, 1981). This may be especially important in case of an island in the sea. Due to the adaptive abilities of birds, habituation to repellent techniques is a serious problem in bird control.The results of audio and visual repellents vary greatly. Similar methods used at different airports may yield completely different or even contradictory results. Therefore, it is nearly impossible to judge the effectiveness of most visual and audio repellents. At many airports, the effectiveness of repellents is assessed by testing in the field.

\section{EXCLUSION}

Bird presence can be denied or discouraged by using physical barriers for buildings, open water, and landfills. Buildings are used by birds as roosting (or even breeding) sites, for example starling and pigeons on ledges or in hangers, and gulls on open water or on rooftops. Favoured areas, such as ledges, setbacks, and flat surfaces can be closed off with netting, screening, spikes, wires, or sticky substances (the latter only having a temporary effect). On flat ledges, metal strips can be applied with an angle greater than 45 degrees. Using curtains of heavy plastic sheets will prevent the use of openings or doorways by birds; making a ceiling with nets or cloth will prevent birds to roost under roofs or shelters (Blokpoel, 1976).

Water bodies such as ponds or lakes can be made inaccessible with wire systems. The grid of the wire system depends on the target species. For gulls, a grid of $6 \times 6$ metres proved to be useful, for waterfowl a smaller grid ( $3 \times 3$ metres) is needed. Exclusion of water is also possible with nets. Exclusion of landfills as a food source (mainly important for gulls) is best done by daily covering of waste. Wire systems have also been successfully used on landfills. Waste sites at meat or fish-processing industries should also be carefully covered (Drury, 1965). Gulls appear to use several feeding sites spread over a large area. It is important to take measures at all potential feeding grounds in wider surroundings than in just the close vicinity (Cogswell, 1969).

Large, horizontal nets have been described as a means of keeping birds away from airport fields. However, such nets make maintenance of the terrain difficult. Experiments have been conducted with heated surfaces, based on the assumption that gulls prefer warm surfaces for roosting or loafing. No positive results were obtained (Blokpoel, 1976).

\section{CHEMICAL REPELLENTS}

In the Netherlands, chemical repellents are not used nor are experiments conducted. A number of chemical repellents are currently used in the United States and Australia (Cleary, 1994). In many cases, experiments with chemicals to harass birds (mainly tried on gulls) have often been unsuccessful except when combined with other deterring techniques. Having a moderate climate with a lot of rain, chemicals are not expected to be successful in the Netherlands (Kuyk, 1981). The use of potentially toxic chemicals may also have legal and ethical complications. Consequently, testing and use of chemicals as bird repellents is not often recommended.

\section{RETA}

In Israel, surface spraying with Reta (aluminium ammonium sulphate) caused a decrease in the number of gulls, although they did not disappear completely except when this method was combined with others. Although the gulls seemed to have become more uneasy and susceptible to sounds, the use of Reta was not 
considered a sufficient method. In several other countries (Denmark, Switzerland and France), tests with Reta failed to produce desired results (Stenman, 1990).

\section{POLYBUTENE}

For keeping birds off roosting surfaces, a number of repellents containing polybutene or polyisobutylene are available. When applied to the surfaces in liquid or paste form, they make landing birds feel uncomfortable. In order to displace the birds effectively, all potential surfaces should be treated with the chemical, and applications repeated every six months to a year, and more often if the surfaces are very dirty. Examples of treatments to include Bird Stop, Roost-no-more, and Bird-X, 4-The Birds as all of them are nontoxic (Stenman, 1990).

\section{METHYL ANTHRANILATE}

Methyl anthranilate is the non-toxic active compound in ReJeX-iT to which birds have a strong aversion, and it is applied on golf courses, landfills, standing water, and temporary pools to keep away gulls, and waterfowl or starling. Although the effectiveness of methyl anthranilate has been demonstrated on several bird species (Ring-billed gull, Mallard), experiments on (captive) Canada Geese foraging on turf, showed no evidence that ReJeX-iT was effective as a grazing repellent. It may be more effective in higher doses and on wild Canada Geese, particularly in combination with other forms of harassment. The effectiveness may also depend on the surface that is being protected. For example, food demands higher concentrations of methyl anthranilate than water (Dolbeer, Belant and Clark, 1993).

\section{NAPHTHALENE}

This repellent, working on the sense of smell, was tested at airfields in the United Kingdom, and applied to the field as 'moth balls'. Results were contradictory.

\section{AMINOPYRIDINE}

Avitrol is an example of a toxic repellent. Bait (preferably grain) is treated with Avitrol and subsequently eaten by the target birds that react with distress behaviour because of the active compound (4aminopyridine). This in turn frightens other birds in the vicinity. A sufficient dose is lethal so by using limited amounts of bait, a flock of birds can be chased away without resulting in fatalities (Cleary, 1994).

\section{AUDIO REPELLENTS}

Birds can temporarily be chased away using sound techniques: pyrotechnics, propane gas cannons, or bioacoustics, but in general, loud noise itself does not seem to bother birds (Blokpoel, 1976).

\section{PYROTECHNICS}

Pyrotechnics are noise-producing devices such as scare cartridges, shell crackers, fireworks, alarm pistols, shotguns, and electronic alarms (the latter being little used). They are often effective, easy, and safe to use and are thus widely used, nearly always in combination with bioacoustics, visual scaring, or shooting. Additionally smoke is occasionally used to scare the birds, and flares are not widely used but tend to have a good effect (Stenman, 1990). Apart from the audio effect of the explosion, there is also a visual effect of light and smoke.

Flares are normally fired from a pistol. At Schiphol Airport, the flares have been replaced by shell crackers that do not leave debris that is dangerous on runways. The effect of shell crackers varies with habituation. Birds can be dispersed to a particular direction by aiming the firing in a certain direction (cartridges). Sirens on vehicles are also used with some success and noise generators along runways are used successfully to scare away Lapwing, gulls and pigeons (Stenman, 1990).

\section{GAS CANNONS}

Propane, carbide, or acethylene gas cannons are less widely used, probably because habituation to them can occur quickly. They can however be very effective on gulls, waterfowl, and other game birds (as birds that are hunted, they associate noise with danger). They can especially be used when migrating birds come in to feed or roost. Frequent relocation, varying the frequency of detonations, and combination harassment techniques will prevent habituation and improve the effect (Godsey, 1997).

\section{BIOACOUSTICS}


Bioacoustics work through broadcasting of pre-recorded bird distress calls, which are specific to bird species, although Godsey (2000) states that non-specific distress calls are the most effective. Experiments with computerized calls have been successful as well. The birds will interpret the calls as an alarm signal and fly away, perhaps enhanced by group behaviour. However, other responses, such as flying towards the source to check out the 'danger', have been reported, creating a potential momentary hazard (gulls, Corvids). Distress tapes are preferably played from a sound system on a vehicle, producing 90 to 100 decibels of sound. Fixed systems become ineffective with time in several countries (Stenman, 1990). After the birds have been identified, a tape with the appropriate call sound is selected, the birds are approached to a minimum of 100 to 200 metres (depending on the local situation), and the call is played for 15 to 20 seconds only to prevent habituation.In the Netherlands, an automatic randomizing system is used to broadcast distress calls and gulls, starlings, and crows can be dispersed with them. Not all species react to bioacoustics (Lapwing, oystercatcher and starling, and the response depends on the birds' behaviour or state (hungry, tired, or breeding birds show less response). In practice, bioacoustics is often used in combination with other measures to prevent habituation. For example, a combination of pyrotechnics, hunting, or incidental killing provides good results in many countries. In Britain, the main problem species react to their distress calls. Before using distress calls, investigations are needed into the problem species, their calls, the circumstances in which the calls should be used, the required quality and equipment, and the best way of reinforcement (Blokpoel, 1976).

\section{ULTRA-SOUND, INFRA-SOUND, RADAR}

These sound sources are generally regarded as not effective in scaring birds. Tests at various locations and under various circumstances have, in some cases, provided contradictory results. There is no proof of any positive effect. Generally, ultra-sound (using very high frequencies) has appeared to be unsuccessful in chasing away birds (Blokpoel, 1976). The hearing range of birds (proven for pigeon, house sparrow and starling), is narrower than that of human beings so sounds that are inaudible to humans are inaudible to birds. Moreover, ultrasound requires much power and quickly loses strength with distance. Contrastingly, one record of successful use of ultrasound was found in literature: at Venice Airport in Italy ultra-sonic equipment was successfully used on gulls. The experimental circumstances in which these results were obtained are however not mentioned (Stenman, 1990).

According to some sources, bird species may be sensitive to infra-sound (low frequency) and use it for navigation. The same may be true for modulated radar, as several observations indicate. According to other sources, however, radar does not seem useful for scaring birds, although studies continue in order to test this possibility. The noise of aircraft engines is being studied to determine if certain frequencies are suitable for scaring birds, as an overlap may exist between frequencies between engine noise and distress calls (MacKinnon, 1996).

\section{XXV. $\quad$ CARCASSES OR MODELS OF DEAD BIRDS}

This method of agricultural origin is widely practiced, with varying results. Dead birds 'wear out' quickly, but their use can be extended by conservation with formaldehyde. Plastic models (dummies) or mounted specimens are more durable, but have less of an effect compared to carcasses. There is also the problem of some animals or birds being attracted to carcasses or models of dead birds instead of being repelled by them (Stenman, 1990).

At Schiphol Airport, many experiments with model gulls have been conducted. Various gull reactions, ranging from virtually no effect to a very strong reaction, have been noted. Posture and placing of the model appear to be important factors in determining the gull's reaction. Sitting or standing models do not deter gulls. Lying birds, with or without spread out wings, provoke a reaction similar to distress calls - flying towards the model, circling and flying away. This effect may last 1-3 months, or only a few days (Stenman, 1990). After some time, birds may settle down within 50 metres of the dead bird. Models hung up are more frightening than those lying on the ground, probably because of the additional movement brought about by wind. A nodding head-tail movement by the models is more successful (Stenman, 1990).

\section{FALCONRY}

The results with falconry vary and success depends on many factors. More research is needed to establish the effectiveness of falconry in reducing the number of birds under various circumstances. Several species of falcon (peregrine, gyr, lanner or saker falcon, and merlin) and Eurasian Goshawk can be trained effectively to aid in bird dispersal at airports. Not only low altitude hunting flights but also high altitudes patrolling flights of raptors are successful in chasing away birds. One advantage is that the falcon is less vulnerable than when hunting. In this respect, falcons are more useful than goshawks, because the latter uses fast low altitude flight. Falconry is practiced in some countries with positive results (e.g. Scotland, Canada, and Spain) (Dolbeer, 1998). 
At John Fitzgerald Kennedy (JFK) Airport, falconry was tested to supplement (and eventually replace) the gull shooting programme. Peregrine, peregrine $\mathrm{x}$ gyr falcon-hybrid and Harris' hawk were flown, typically in flights simulating hunting. In such settings, gulls will react with formation flight. Additional pyrotechnics and distress calls were used at JFK and during the overlap of shooting and falconry, less gulls were shot. When shooting was stopped and falconry was continued (received positively by public and media), there was no significant reduction of bird strikes compared to the period prior to the shooting. In other cases, falconry did not appear to be a cost-effective method. In the Netherlands, falconry was tested at Schiphol Airport with model aircraft, and this method was also used at Vliegbasis Leeuwarden airport until 1974 (Stenman, 1990).

An advantage with falconry is that habituation does not occur, because a real danger is involved. However, there are several limitations: training and maintenance is difficult, a full-time team is required, the birds can only be flown during daylight, and good weather and flying is not possible just after feeding or during moult (Kuyk, 1981). In many cases, falconry was abandoned because of such limitations. When considering use or testing of falconry, the local situation and limitations should be taken into account. Overhead silhouettes of raptors have been successful to some degree, however, habituation quickly occurs when there is no actual danger associated with them (Cleary, 1994).

\section{MODEL AIRCRAFT}

Remote-controlled model aircraft, shaped in the silhouette of a bird of prey, has been successfully tested on gulls in the Netherlands and on dunlin in Canada. The small aircraft are flown across or towards the target birds by remote control, imitating the movement of raptors. Tests in France showed that shape, colour, and noise of the model did not influence results, but that the way the model was piloted was more important. Maneuvering the aircraft is difficult, especially in windy circumstances and in busy aviation traffic (Blokpoel, 1976).People, vehicle patrols, and slow arm waving has been successful in deterring gulls, perhaps because the movement imitates the flight of a large raptor (e.g. white-tailed eagle) (Kuyk, 1981). There will be many variations on this theme, such as imitation wings fixed on a vehicle, etc. However, little information on this was found in literature. The mere presence of people or the bird patrol vehicle is enough to scare away some species. Persons of models holding shotguns are successful, especially where hunting is common practice. In some cases however, habituation to visual scaring is less than to other dispersal techniques (Stenman, 1990).

\section{DOGS}

One literature source mentions the use of border collies to disperse geese. This was reported to be successful under certain circumstances, but the nature of these circumstances is not explained (Dolbeer, Belant and Clark, 1993).

\section{MYLAR-TAPE}

In agriculture, mylar tape is used as a 'scarecrow' to keep birds out of crops. Twisted strands of this tape are stuck to sticks. They then move in the wind and flash in the sun, and this frightens the birds. Although the use of mylar-tape is mentioned in relation to bird control, no examples of use at airports were found (Cleary, 1994).

\section{XXX. $\quad$ EYE SPOTS}

Using eye spots on flags, balloons, or doors, has no positive results as birds get used to them very quickly (Stenman, 1990). Eye spots on aircraft (e.g. engine spinner) are studied with a negative to a $20 \%$ reduction in bird strikes (Stenman, 1990).

\section{LIGHTS}

Various light sources (search, rotating, flashing, laser, or strobe lights) are sometimes used, and in combination with mirror systems to keep birds away from aircraft areas. Flashing (anti-collision) lights are also used on aircraft; birds are better able to detect an approaching plane and avoid it. Flashing lights are also used on bird patrol vehicles. The flashing frequency should be less than 100/sec.Search lights in darkness have shown to have some scaring effect on gulls and a strong beam can scare them from a distance of up to $800 \mathrm{~m}$. Tests have indicated that blue light may be more effective than other coloured lights in scaring off the birds, perhaps due to a higher visual sensitivity to 'blue' wavelengths. Fixed strobe lights have been successful inside buildings, but not outside (Stenman, 1990). Laser is not considered very successful; although in France there have been good results with a portable helium-neon laser. However, test results also showed that the required laser intensity would be dangerous to animals and man (Blokpoel, 1976). It has been concluded that the approach-lights alongside landing strips reduce bird strike (during daylight) by 50\% and it is probable that improve a bird's timely detection of an approaching plane (Thorpe, 1977).Care should be taken with the use of lights at night, because migrating passerines are known to be attracted to lights. Especially during falls, 
increased numbers of passerines have been recorded at or around lighthouses, lightships, or large illuminated industrial areas along the coast.

\section{WINDMILLS}

Mobile windmills have a medium effect in controlling birds. Regular shifting is necessary and the method is susceptible to habituation. This technique is only practiced in the Netherlands (Stenman, 1990).

\section{UNSUCCESSFUL VISUAL REPELLENTS}

Many methods have been tried for scaring birds away from airports but without success including: Stuffed or plastic owls in buildings. Such owls attract passerines and crows. Rubber-snakes are said to keep birds out of buildings but do not seem to work in practice. Other examples are blue balloons, coloured smoke, dyeing of grass, and brightly coloured panels (Blokpoel, 1976). A significant disadvantage of visual repellents is that they are only effective during daylight.

\section{HABITUATION}

Habituation will occur to any audio or visual repellent that does not pose a noticeable threat or danger to the birds themselves. Birds generally react to 'new' objects, explaining the (initially) good results of a repellent. Repeated use without additional reinforcement will in time make any effect disappear because the birds will learn that there is no actual danger involved. Frightening techniques should only be used after careful study and planning; indiscriminate use will accelerate habituation (Bird Strike Committee USA, 1999). Varying use and location, switching between different techniques, and combining pyrotechnics and distress calls with other control measures, are necessary for harassment successful. As long as an attractive site is still present and accessible, birds will keep returning to it. In this view, habitat modification and exclusion compare favourably to audio and visual repellents (Cleary, 1994).

\section{POPULATION MANAGEMENT}

Generally, population management can be a very effective control method. Four perspectives can be distinguished: reduction of the (local) population of target birds, ad hoc elimination of individual birds that constitute an acute danger, harassment of groups, or reinforcement of other control techniques.

Population management consists of capturing or killing target birds. Negative aspects of population management apart from killing birds are that the large-scale effect is nonpermanent, the (public) reputation is bad, and it can be costly. In most countries, a large number of birds are under protection, although official permits can be obtained for specific purposes. Killing birds is generally considered as a 'last resort', only used when other techniques fail. In practice, however, there is often a need for quick and adequate action for reducing bird populations around airports (Blokpoel, 1976).

\section{CAPTURING}

Physical methods of reducing bird populations around airports include trapping and netting. Live trapping is a selective method and may offer a solution for birds that are hard to scare off. For instance, snowy and great horned owls are trapped at Canadian airports in winter. They are then banded and released elsewhere. Trapping cages can work well, especially when provided with food, water, cover, and decoy birds (for instance on corvids or raptors (Lensink and Dirksen, 1999). Cages need to be moved regularly and checked at least daily. Capturing small flocks of birds is also possible with cannon or rocket nets.Cannon netting takes considerable preparation: they must be carefully installed, target birds must be fed (or trained by baiting) right in front of the net. The net size may be varied according to the expected number of birds. The cannons fire projectiles which pull the net over the feeding birds. Rocket nets are smaller but can be launched from a person's shoulder and thus are suited for ad hoc use on individual birds or small flocks. In the United States, a number of capturing devices for individual live raptors are used, such as 'bal-chatri' noose carpets or sliding padded pole traps (Cleary, 1994). Traps are generally little used as the capture and removal of birds is time-consuming and costly. Also, displaced birds may return or others may take their place. Useful results with displacement are only achieved in the case of individual raptors (Blokpoel, 1976). 


\section{CHEMICAL CAPTURE}

Chemical capture works by feeding target birds with bait that is treated with a sedative or immobilizing toxicant, which puts them to sleep and enables their capture. Recommended baits are corn (pigeons or waterfowl) and bread (individual birds). Alpha chloralose (A-C), for example, is used as bait in the United States, as well as in a lethal dose on herring gulls in Denmark Stenman (1990). Birds become capturable in 30 to 90 minutes, recovery occurs within 8 to 24 hours. Pre-baiting is necessary to ensure the success of this method.

\section{KILLING}

Population management aimed at a reduction of the number of bird species implies that the killing rate must be higher than the natural death rate. Most target species tend to be very numerous or increase in number (gulls, waterfowl, and starling), so killing inadequately reduces their number, unless it is done on a very large scale. However, killing is effective on local breeding colonies. Killing great numbers of birds is, apart from difficult an expensive, generally not an acceptable control method and may have an adverse effect. Decreasing bird numbers through killing reduces competition between the surviving birds for resources, so the remaining population becomes 'healthier' (Stenman, 1990). In the Netherlands, managing the population of gull colonies is hardly practiced, because gulls do not cause many problems in the breeding season (Kuyk, 1981).

Killing individual birds as a reinforcement of repellent techniques is widely used and helps avoid habituation and stimulate the scaring effect. Killing is mainly done by shooting. Leaving a carcass after shooting for other birds to see it has a scaring effect that lasts 24 hours. Lethal means of population management are shooting, lethal trapping, poisoning and destroying of the birds' eggs or nests. One example of the introduction of predators as a bird deterrent method was found in existing literature (ref?). Relevant methods are discussed below.

\section{SHOOTING}

Shooting eliminates the target bird, frightens the rest of the flock, and reinforces other repellent techniques. Surviving birds will be scared by the noise and the death of one bird, and will associate this with the other repellents. This method is therefore very effective. At the JFK International Airport for instance, bird strike was reduced to $90 \%$ by shooting gulls flying over the airport. These birds were mainly laughing gulls, originating from an expanding breeding colony nearby; during a six-year shooting period, 52,235 gulls were killed (Dolbeer, 1998).Observations indicated that local breeders that are shot were replaced by birds emigrating from other (expanding) colonies (MacKinnon, 1997). Apart from the disadvantage of killing many birds, shooting is expensive and demands a lot of effort. Professional use of firearms, study of regulations, and notification of local authorities, are important aspects of this control method.For waterfowl, hunting is effective in reducing the local population, as well as repelling ducks or geese. Gulls tend to learn very quickly and react to approaching vehicles or people by keeping a safe distance or staying out of shooting range (this behaviour causes the reinforcing effect of shooting on harassment). Thus, shooting gulls may soon become very difficult, unless it is practiced on birds flying overhead on a sleeping or feeding fly route (MacKinnon, 1997).Occasional shooting of individual birds is practiced in many countries, depending on their regulations. In the Netherlands, shooting at civil airports is only used as reinforcement of the usual techniques and to reduce the number of hazardous breeding species (oystercatcher, lapwing, grey heron, and pheasant) (Stenman, 1990).

\section{POISONING}

For poisoning target birds, oral and contact toxicants are used in the United States and not in the Netherlands) (Stenman, 1990). Toxicants have mainly been used in agriculture, but they are also used at airports. Oral toxicants are applied by baiting and contact toxicants by treating perches. Oral toxicants require a careful study of the target birds' behaviour, favoured sites, carefully designed pre-baiting, careful handling and controlling of toxicant and bait. Pre-baiting is the determining factor for success. Location and timing of prebaiting should be adjusted to the birds' feeding behaviour and daily routine, and should be conducted two to three weeks before applying the toxicant. The bait should be of good quality and of fine, uniform structure (higher surface-volume ratio). It should not be applied before ensuring only target birds feed on the bait. Unused bait and dead birds should be properly removed (Cleary, 1994). An example of an oral toxicant (registered in the United States) is 3-chloro-p-toluidine hydrochloride, which is used for gulls' colonies to reduce predation of nearby nesting colonies of other species. It metabolizes quickly, the metabolites are not toxic, and there is no secondary toxicity on animals eating killed birds. An example of a contact toxicant (registered in the United States) is fenthion ('Rid-a-Bird' perches). It is used for starling, pigeons, and sparrows, and applied on or in (farm) buildings, power plants, bridges, etc.

Secondary toxicity occurs so dead birds should be properly removed from the site. It is not recommended to use perches outside buildings because non-target birds may also consume the toxic chemicals. There is an example 
of successful application of a strong sleeping drug in a gull colony in New Zealand, after which many birds were captured (Caithness, 1969).

\section{DESTRUCTION OF EGGS AND NESTS}

Breeding populations of waterfowl or gulls can be a problem near airports. This can be discouraged by removing their eggs and nests. When clutches are complete, all eggs and nests should be removed from the colony every two to three weeks, until all breeding efforts stop (Cleary, 1994). Another possibility is to spray the eggs with an emulsion of oil and water containing $10 \%$ formaldehyde. The eggs will die without decomposition (which may induce laying of a second clutch). Kuyk (1981), mentions that this method is only workable in smaller colonies, although it was used effectively at a large herring gull colony near the airport of Copenhagen. Egg-shaking is also used as a method and it should start after the clutch is complete and breeding begins. When incubating is already progressed, shaking loses its effect. To determine the state of incubation, the flotation test is suitable.

Eggs and nests should not be destroyed after shaking, before another period of incubation has elapsed, when birds do not attempt to re-nest (Cleary, 1994).

\section{PREDATORS}

In the United States, herring gull colonies on small islands have been eliminated within 2-4 years by introduction of fox and racoons (predation of both birds and eggs). However, these predators were not able to survive without additional feeding. In contrast to colonies, the presence of predators at gull-roosts does not appear to be effective, because roosting birds will fly sooner than breeding birds.

To prevent escape of predators and colonization of adjacent terrain, areas where predators are introduced should be completely fenced off. In practice, this will be very difficult (except on islands). The problem with introducing predators is that they have to be controlled to maintain a certain population density, and they too may pose a strike risk to aircraft (Kuyk, 1981).

\subsubsection{Airport safety management}

Safety is a priority in the aviation industry. The industry has demonstrated diligence and learned from its mistakes, and continually improving the safety levels. This effort reduced accident rates by the mid-1980s. Since then, the fatal accident rate in air transport operations has remained fairly stable, despite a growth in traffic during the same period. This trend implies little improvement in safety in terms of operation/accident ratio, and suggests that as traffic grows, the total number of accidents grows accordingly (Ayres, 2009).

The ICAO, recognizing these facts and that "the public's perception of aviation safety is largely based on the number of aircraft accidents rather than the accident rate", issued a resolution to "reduce the number of accidents and fatalities irrespective of the volume of air traffic". The ICAO further provides guidance on how to achieve this resolution, including the recommendation to "develop a civil aviation safety management framework and providing recommendations for improving safety" (ICAO, 2004).

In conclusion, in recent years a great deal of effort has been devoted to understanding how accidents happen. It is generally accepted that most accidents result from human error, which one could conclude indicate carelessness or lack of skills on the job, but such a statement is not accurate. Accident investigators are finding that human error is only the last link in a chain that leads to an accident. Accidents cannot be prevented by changing people; they can be prevented only when we address the underlying causal factors (Ayres, 2009).

There are two ways of thinking about safety: a means of avoiding costs as many aviation organizations have been bankrupted by the cost of a single major accident; and efficiency. Ayres (2009) says safety and efficiency are positively linked. Safety pays off in reduced losses, enhanced productivity, and lower insurance costs.

\subsubsection{Disaster risks and preparedness in the aviation sector}

Once a disaster has occurred, a set of activities has to be put in motion, aimed at firstly satisfying the immediate needs of the victims, their rehabilitation, and the reconstruction of any infrastructure that may have been damaged or destroyed. According to Kapoor (2009), short and long term recovery measures include returning vital life-support systems to minimum operating standards; public information and health and safety education; economic impact studies; and counseling programmes. This requires certain procedures to be followed as haphazard response can sometimes be problematic. Policies and objectives should actually guide the recovery process, and should have been put in place for some time, tested, and proven beyond doubt (FEMA, 2006).Coordination is an essential ingredient in a disaster risk preparedness plan. This means that arrangements and preparations are put in place not only to prevent a disaster, but also to be implemented once a disaster occurs. Such plans must be both horizontal and vertical in terms of duty allocation among all stakeholders. The team should be on call 24-hours a day so that in case of an emergency there is no delay in response (Salvano, 2002). 
The resources that add value to professional training should back this team. Without preparedness, the response and recovery operation will rapidly disintegrate. For effective response to be achieved, however, a structure for decision-making and coordination of the action plan, and the actual response must be put in place. In terms of disaster relief operations, the range of relief requirements is normally very extensive. Some of the major requirements include shelter, food, medicine, communication and logistics systems, social workers and counselors, and a multiplicity of other things (UN/ISDR, 2008).To promote disaster risk preparedness, the ultimate objective should be to have plans agreed upon by all stakeholders, which are implementable given the available material and manpower. Over-ambitious plans, especially with inadequate resources, are bound to fail and lower the credibility of the organization in the eyes of the public. Indeed, any disaster risk preparedness plan must have adequate resources committed and readily available (Salvano, 2002).For disaster response and recovery plans to be effective and successful, it is important for community to know what to do in case of a disaster and how to do it. This is defined as empowering the community to participate in disaster recovery (ISDR, 2003). For this reason, an essential part of a disaster risk preparedness and recovery plan is creating awareness among those who may be threatened by the disaster. This includes people residing near the airport.

\subsubsection{Phases of a disaster}

Disaster management is a cyclical process; the end of one phase is the beginning of another, and one phase does not have to be completed for the next to take place. Often several phases are taking place concurrently. Timely decision-making during each phase results in greater preparedness, better warnings, reduced vulnerability, and/or the prevention of future disasters. The complete disaster management cycle includes the shaping of public policies and plans that address the causes of disasters or mitigate their effects on people, property, and infrastructure (Carrilo, 2010).

\section{Mitigation and preparedness phases}

The mitigation and preparedness phases occur as improvements are made in anticipation of an event. By embracing development, a community's ability to mitigate against, and prepare for a disaster, is improved. As the event unfolds, disaster managers become involved in the immediate response and long-term recovery phases.

\section{Emergency phase}

When disaster strikes, there is a major disruption of the local community. Mitigating measures against the disaster must immediately be taken. Emergency response activities are those carried out during the actual emergency or immediately prior to it. This may involve emergency assistance during the disaster, and actions taken in the immediate aftermath during when the community is rather disorganized and basic services and infrastructure are not fully functioning. The impact phase of a disaster can vary from the slow, low-threat buildup associated with some types of floods, to the violent, dangerous, and destructive outcomes associated with tornadoes and explosions. The greater the scope, community destruction, and personal losses associated with the disaster, the greater the psychosocial effects that result (Garatwa and Bollin, 2002).

Depending on the characteristics of the incident, people's reactions range from constricted, stunned, shock-like responses to the less common overt expressions of panic or hysteria. Most typically, people initially respond in confusion and disbelief, and focus on their survival and physical well-being and that of their loved ones. When families are in different geographic locations during a disaster (e.g. children at school, adults at work), survivors will experience considerable anxiety until they are reunited as family members.

\section{Response phase}

The response or relief phase refers to the time period when humanitarian assistance to save lives and to provide essential supplies to those most affected begins. It includes such activities as search, rescue, evacuation, provision of shelters, first aid, emergency medical care and protection, temporary restoration of transportation and communication routes, preliminary repairs to essential public utility services, and early actions to register victims and record damage to public and private property. This stage may vary in its duration but, in general, it is relatively brief, depending on the magnitude of the disaster (Garatwa and Bollin, 2002).

\section{Rehabilitation and reconstruction phases}

The rehabilitation or transition stage includes activities required to return normality to the affected areas and communities. It includes non-definitive repairs to housing and buildings, and to transport and public utility service infrastructure. Problems related to the emotional and psychological recovery of the inhabitants of the regions affected by the disaster are to be addressed here. Return to work, creation of new jobs, availability of loans and financial resources, and immediate start-up projects related to the consequences of the disaster, are among recovery measures that help victims and affected communities. 
Finally, the reconstruction phase includes activities designed to rearrange the affected physical space and environment, and enable the allocation of resources in accordance with the new social priorities arising from the effects of the disaster (Garatwa and Bollin, 2002).

\subsubsection{Disaster risk preparedness in the aviation sector in Africa}

Overall, mismanagement and poor infrastructure have been identified as the greatest handicaps and leading causes of airport accidents. The best way to reduce Africa's airports accidents is by assigning the right people to the right places while emphasizing training and professionalization of departments associated with management of ports. This study provides evidence that aviation disasters in Africa are real and pose a critical challenge to the development and sustainability of the industry and region. It is for this purpose that this study assesses the preparedness of Wilson Airport for prevalent disasters and risks. Although aircraft accidents are rare, maintaining compatible land uses around airports helps to reduce the risk to those living near airports, as well as those persons travelling by air when they do occur. Studies assess trends in aircraft accident locations and their relationship to the ends of runways to define zones of risk.The National Transport and Safety Board (NTSB) conducted a study that assessed aircraft accident statistics from 1978 to 1987 . It concluded that of the 500 accidents in the data set, only 246 were relevant to the study of accident locations. A subsequent study by the same body entitled The Development of an Accident Database to Structure Land Use Regulations in Airport Runway Approach Zones, Part II, 1998, included 873 accidents between 1983 and 1992 (Cooper, 1998). It has been recommended based on the findings of these two studies, that additional data is necessary when accident and incident reports are filed. For example, the precise location of the accident, the extent and location of the debris field, the point of take-off or touchdown, information regarding the surrounding terrain, and land uses.

Additionally, an assessment of the amount of risk associated with land use incompatibility is necessary. For example, in some discussions, people who support compatible land use planning argue that while the probability of an aircraft accident happening in any location is relatively small, it only takes one accident for catastrophic consequences. Others who are not as favourable to this planning effort argue that the risk of an accident is so minute that there is little reason to plan for it. Consequently, local communities need to assess the general risk level of an aircraft accident and its impact to them and their property.

The United Kingdom and the Netherlands have increasingly performed risk analyses in developing land use compatibility guidance. The results of these European studies, along with a study conducted in the United States by the Minneapolis-St. Paul International Airport Joint Airport Zoning Board, suggest current airport land use compatibility criteria may overstate the risk to people and property on the ground. Models developed by the United Kingdom National Air Traffic Services Limited illustrate areas of risk result in a triangular contour with the base adjacent to the end runway and tapering to a point away from the runway.

As a result of these findings from the European community, it would be desirable to have the development of a risk model to determine land use compatibility criteria that could be applied at different airports within the United States, based upon the additional aircraft accident data that is now available. An additional 17 years of data has been collected since the 1992 Cooper Study (1998). This model is available for use by state and local planners and elected officials, as well as airports and consultants, to use for the analysis of risk at an airport. Availability of this model would help to establish a more rational and customized approach in defining criteria for airport land use compatibility and acceptable levels of risk.It should be noted that additional guidance would be necessary to accompany this sort of model. The guidance will provide local policy decision makers to determine acceptable levels of risk compared to the tradeoff for development opportunities in order to reduce risk of aircraft accidents. The willingness will vary from community to community and would need to be based upon local assessment of the potential risks versus the anticipated cost, should an accident occur.

\section{AVIATION DISASTERS IN KENYA}

Kenya has not implemented a safety management system in her aviation industry (Mokaya and Nyaga, 2009). As of 2006, the country has been classified as non-compliant with the International Civil Organization (ICAO) regulations. The aviation association has actually criticized the lethargy exhibited by the Kenya Aviation Authority (KAA) in terms of ensuring compliance to these standards and regulations especially since Wilson Airport is a busy airport. Some literature nevertheless shows Kenyan airports are well-equipped in fire fighting and effective fire fighting capacity (Halimu, 2007). However, this fire fighting capacity only covers limited areas of the airports. This then is an indication of institutional weakness that may limit proper management of disasters when they occur. 


\section{DISASTER MANAGEMENT IN KENYA}

Disasters in Kenya have assumed both natural and human-induced characteristics (Nabutola, 2004; Onywere, 2005; Mutugi and Maingi, 2011; Akali, Khabamba and Muyinga, 2011). However, a fairly good number of them are weather-related and occur as natural disasters not man-made ones (Onywere, 2005). Natural disasters are induced by hazards such as floods, droughts, landslides and lightning, etc. Over the last two decades, a considerable number of human induced disasters caused by hazards such as traffic accidents, civil conflicts, and terrorism have taken place in Kenya (Omari, Bosire-Ogechi and Otike, 2011). Disaster management in Kenya has not developed to the extent where systems are fine-tuned to effectively and efficiently prevent, control, and manage disasters. Mawanda (2003), puts it that locally, resources are geared towards recovery and reconstruction, rather than prevention or appropriate response. In addition, air disasters have been left out in research, particularly in Kenya, as studies have focused on other disasters. For example Kiema-Ngunnzi (2002) looked at recovery strategies for the 1998 Nairobi bomb blast victims within the Teachers' Service Commission. In order to prevent, control, or even mitigate any disaster, the causes of the problem must be brought to the fore.Lack of disaster risk preparedness has remained one of Kenya's enduring development challenges. Most of the disaster response initiatives in Kenya tend to be ad hoc, uncoordinated, and short-term measures, mainly in the form of emergency relief services to the worst-affected areas. There is lack of recognition of the interrelationship between disaster risk preparedness and unsustainable production and consumption patterns (Republic of Kenya, 2009a).Despite the availability of personnel in Kenyan airports to deal with air crashes or disasters, it would seem that their preparedness in all these airports, including JKIA, is grossly wanting. For example, in a simulation of disaster risk preparedness at the JKIA in June 2002, it took 37 minutes for ambulances and fire engines from outside the airport to get to the airport (Mirichu, 2004). While there have been impressive humanitarian relief efforts in times of crisis, particularly related to natural disasters in Africa, Holloway (2003), says that disaster vulnerability and risk have not been considered important for sustainable development planning. In Kenya, resources have been allocated more to relief and rehabilitation efforts than prevention. This is a major shortcoming on the part of the government and other stakeholders in disaster mitigation. For example, according to the Kenya Red Cross Society - KRCS (2009), a fire outbreak in Nakumatt Downtown Supermarket in Nairobi in January 2009, resulted into unnecessary destruction. In actual fact, the city planners should have foreseen the possibility of such a disaster and advised on construction plans before the disaster happened.

\section{DISASTER POLICY, INSTITUTIONAL AND REGULATORY FRAMEWORKS IN KENYA}

The lessons learned from the major events of the last decade have triggered new laws and regulations that expand prevention strategies and augment response capabilities. The same disaster risk preparedness and response planning standards that govern cities, counties, States, are now being considered from an airports perspective. As planning moved beyond a focus on surviving a nuclear weapon attack to comprehensive disaster planning, so, too, are airport managers expanding contingency plans from those based primarily on aircraft crashes to all potential emergencies (Stambaugh, 2009).Increasing regularity of different types of disasters in Kenya prompted the government through the Office of the President to formulate a National Policy On Disaster Management (GoK, 2009). The policy was developed to avoid disasters being mitigated in a reactive and poorly coordinated manner. This government policy document provides general guidelines for development of strategies to address disaster issues. Specific sector guides however ought to be developed separately (GoK, 2009). For instance, in the aviation sector, the onus of developing such policies is entrusted to the Kenya Civil Aviation Authority, (Munyi, 2011; Mokaya and Nyaga, 2009). As of 2009, a safety management system for the sector had not been developed (Mokaya and Nyaga, 2009) despite Kenya having had signed the International Civil Aviation Convention while aviation disaster risks in our airports and air spaces.

Other aviation policy analysis emphasise the need for policy benchmarking especially with international standards (Oladele, 2005). This is especially through regional and global identification of best practices and domesticating them to local or national levels.

\subsubsection{Socio-economic and environmental factors}

Actions to lessen environmental effects have increased the costs of development, more so when incompatible land uses are present. Airport sponsors need to conduct more comprehensive environmental assessments, incur higher environmental mitigation costs, and undertake more extensive public outreach efforts (GAO, 2000).The National Environmental Policy Act (NEPA) of 1969 calls for an environmental review of federal actions, including airport expansion projects. In particular, noise-mitigation measures include acquiring noise-sensitive properties, relocating people, modifying structures to reduce noise, encouraging compatible zoning, and assisting in the sale of affected properties. In addition to these efforts, most airports have voluntarily established some type of noise monitoring system, and conduct public outreach and education programmes 
(GAO, 2000; GAO, 2007). Since the early 1980s, the federal government has issued grants to mitigate noise around many airports. Since the early 1990s, the FAA has allowed airports to impose passenger facility charges for that purpose. The FAA has provided about $\$ 5$ billion in Airport Improvement Program (AIP) grants, and airports have used about $\$ 2.8$ billion in passenger facility charges (PFC) for Part 150 noise mitigation studies and projects. In total these funding amount to nearly $\$ 8$ billion (GAO, 2007). In the last 10 years, the FAA has also spent about $\$ 42$ million on research to characterize noise and improve prediction methods, including developing a capability to determine the trade-offs between noise and emissions, and quantify the costs and benefits of various mitigation strategies (GAO, 2007). The safety of aircraft and their occupants, as well as people on the ground, is a very important concern in aviation policy development. Aviation accident rates have fallen over the years due to relentless efforts to develop strategies that reduce the occurrence of accidents and to promote technologies, programmes and practices that enhance aviation safety. Air transport has become the safest way to travel with 0.75 accidents per million flights in 2007 (International Air Transport Association \{IATA\}, 2008). When they do occur, aviation accidents are costly. They can result in substantial loss of lives, injuries, property damage, and substantial monetary costs associated with hospitalization, accident investigation and, in certain cases, litigation. Accident data suggest that aircraft accidents in the vicinity of airports tend to occur near runway ends under the approach and departure flight paths. The presence of tall structures, visual obstructions, and land uses that attract wildlife in or near the runway approach and departure areas, pose flight safety hazards, and increase the risk of aircraft accidents.

\section{METHODOLOGY}

This study was carried out at Wilson airport located in Nairobi West. The airport is strategically located only about 5 kilometers from Nairobi city centre. The descriptive design was applied in this study to analyze and describe the effects of land use changes on airport and flight safety in a rapidly growing aviation sector. A total of 216 respondents were sampled for the study including 30 aviation regulators, 30 air operators, 6 service providers, and 150 members of the community. This population has been targeted due to its significant role in either determining issues of preparedness for disaster and risk or being potential causes of disasters and risks at Wilson airport. This study collected primary and secondary data. Primary data was collected by use of questionnaires, interview guide and Focused Group Discussions while Secondary data were collected from written or published records and maps from the Kenya National Bureau of statistics. Qualitative data was analysed by use of descriptive statistics such as frequencies and percentages while qualitative data was analysed using content analysis.

\section{FINDINGS OF THE STUDY}

4.1Socio-economic and environmental considerations put in place in designing disaster risk preparedness measures amongst stakeholders at the airport

This section presents the results on socio-economic and environmental considerations such as the location of the airport and environmental factor effects.

\subsubsection{Assessment on whether the location of Wilson Airport is a threat to its security}

Aviation regulators and air operators were asked to indicate whether the location of Wilson Airport is a threat to its security as far as geographical, environmental, social, and economic factors are concerned. The study found that $37(65 \%)$ of respondents indicated that it is, while $20(35 \%)$ indicated it is not. The National Environmental Policy Act (NEPA) of 1969 calls for an environmental review of federal actions, including airport expansion projects. Noise mitigation measures include acquiring noise-sensitive property, relocating people, modifying structures to reduce noise, encouraging compatible zoning, and assisting in the sale of affected property $(\mathrm{GAO}, 2000,2007)$. All these are strategies aimed at ensuring that the location of an airport is not a threat to the population living around it and also to ensure a conducive environment for effective airport operations.

\subsubsection{Effect of environmental factors on the safety of the airport}

Regarding the effect of the environmental factors on the safety of the airport, the study found that a majority of respondents $51(89.5 \%)$ indicated that the proximity of the airport to Uhuru Gardens affects its safety and security to a very large extent; 40 (70.2\%) respondents indicated that the location of supermarkets and big restaurants such as Carnivore Restaurant affects the safety and security of the airport to a very large extent; $39(68.4 \%)$ indicated that the development of slum settlements near the airport has an effect on the safety of the airport to a very large extent; 24 (42.1\%) indicated that the location of the airport near Nairobi National Park affects the safety of the airport to a very large extent; and 37 (64.9\%) indicated that the location of the 
airport adjacent to Lang'ata Road has a neutral effect on the safety of the airport. The results are as presented in Table1 below.

Table 4.13: Effect of environmental factors on the safety of the airport

\begin{tabular}{|c|c|c|c|c|c|c|c|c|c|c|c|c|}
\hline \multirow[t]{2}{*}{ Statement } & \multicolumn{2}{|c|}{$\begin{array}{c}\text { Very } \\
\text { large } \\
\text { extent }\end{array}$} & \multicolumn{2}{|c|}{$\begin{array}{l}\text { Large } \\
\text { extent }\end{array}$} & \multicolumn{2}{|c|}{$\begin{array}{c}\text { Neutr } \\
\text { al }\end{array}$} & \multicolumn{2}{|c|}{$\begin{array}{l}\text { Small } \\
\text { extent }\end{array}$} & \multicolumn{2}{|c|}{$\begin{array}{l}\text { No } \\
\text { extent } \\
\text { at all }\end{array}$} & \multicolumn{2}{|c|}{$\begin{array}{c}\text { Total } \\
(\%)\end{array}$} \\
\hline & $\mathrm{F}$ & $\%$ & $\mathrm{~F}$ & $\%$ & $\mathrm{~F}$ & $\%$ & $\mathrm{~F}$ & $\%$ & $\mathrm{~F}$ & $\%$ & $\mathbf{F}$ & $\%$ \\
\hline $\begin{array}{l}\text { Location of the airport } \\
\text { adjacent to Lang'ata } \\
\text { Road }\end{array}$ & 37 & 64.9 & 10 & 17.5 & 2 & $\begin{array}{l}3 . \\
5\end{array}$ & 8 & 14 & 0 & 0 & 57 & $\begin{array}{l}10 \\
0\end{array}$ \\
\hline $\begin{array}{l}\text { Noisy environment due } \\
\text { to the activities going } \\
\text { on around the airport }\end{array}$ & 22 & 38.6 & 14 & 24.6 & 0 & 0 & 5 & 8.8 & $\begin{array}{l}1 \\
6\end{array}$ & 28.1 & 57 & $\begin{array}{l}10 \\
0\end{array}$ \\
\hline $\begin{array}{l}\text { Development of slum } \\
\text { settlements near the } \\
\text { airport }\end{array}$ & 39 & 68.4 & 13 & 22.8 & 0 & 0 & 5 & 8.8 & 0 & 0 & 57 & $\begin{array}{l}10 \\
0\end{array}$ \\
\hline $\begin{array}{lrr}\text { Location } & \text { of } \\
\text { supermarkets and big } \\
\text { restaurant such as } \\
\text { Carnivore }\end{array}$ & 40 & 70.2 & 10 & 17.5 & 0 & 0 & 7 & 12.3 & 0 & 0 & 57 & $\begin{array}{l}10 \\
0\end{array}$ \\
\hline $\begin{array}{l}\text { Location of the airport } \\
\text { near Nairobi National } \\
\text { Park }\end{array}$ & 24 & 42.1 & 20 & 35.1 & 3 & $\begin{array}{l}5 . \\
3\end{array}$ & 10 & 17.5 & 0 & 0 & 57 & $\begin{array}{l}10 \\
0\end{array}$ \\
\hline $\begin{array}{l}\text { Location of the airport } \\
\text { near tourist attraction } \\
\text { sites such as Uhuru } \\
\text { Gardens }\end{array}$ & 51 & 89.5 & 5 & 8.8 & 0 & 0 & 1 & 1.8 & 0 & 0 & 57 & $\begin{array}{l}10 \\
0\end{array}$ \\
\hline
\end{tabular}

Source: Author (2014)

The respondents were further asked to mention other geographical, environmental, social, and economic factors posing a threat to the safety and security of Wilson Airport, and respondents mentioned the presence of tall structures, visual obstructions, and land uses that attract wildlife in or near the runway approach and departure areas.

\section{SUMMARY OF FINDINGS OF THE STUDY}

The study found that $37(65 \%)$ of respondents indicated that the location of Wilson Airport is a threat, while $20(35 \%)$ of the respondents indicated that the location of Wilson Airport is not a threat to the security and safety of the airport. Regarding the effect of environmental factors on the safety of Wilson Airport, the study found that $51(89.5 \%)$ of respondents indicated that the location of the airport near tourist attraction sites such as Uhuru Gardens negatively affects the safety and security of the airport to a very large extent. The study also found that $40(70.2 \%)$ of respondents indicated that the location of supermarkets and big restaurants such as Carnivore affect the safety and security of the airport to a very large extent; 39 (68.4\%) of the respondents indicated that the development of slum settlements near the airport has an effect on the safety of the airport to a very large extent; $24(42.1 \%)$ of respondents indicated that the location of the airport near Nairobi National Park has an negative effect on the safety of the airport to a very large extent; and 37 (64.9\%) of respondents indicated that the location of the airport adjacent to Lang'ata Road has a neutral effect on the safety of the airport. Other environmental factors included: thepresence of tall structures, visual obstructions, and land uses that attract wildlife in or near the runway approach and departure areas. Thus, socio-economic and environmental consideration is a determinant of disaster risk preparedness at Wilson Airport.

\section{CONCLUSION}

The study concludes that there are socio-economic and environmental factors that pose a threat to the safety and security of Wilson Airport. This is evidenced by the location of the airport near tourist sites like Nairobi National Park and Uhuru Gardens, supermarkets, big restaurants, developments of mitumba slums, the presence of tall structures, visual obstructions, and land uses that attract wildlife in or near the runway approach and departure areas of the airport. 


\section{RECOMMENDATIONS}

As revealed from the findings of the study, there are changes in the socio-economic and environmental surrounding which pose a threat to the safety of Wilson airport. The study therefore recommends that socioeconomic and environmental factors should be considered within and around Wilson Airport as they pose threats to the security and safety of the airport. This can be done by regulating the activities going on around the airport and adjusting to the environmental factors through the adoption of better technologies for the management and operation of the airport. The major hindrance to this recommendation is that the proximity of the airport to the surrounding human settlements such as the Mitumba slums, Phenom Estate and Five Star Estate may generate waste, which may attract birds and pose a threat to the aircrafts along the flight paths.

\section{REFERENCES}

[1] Akali, N. M., Khabamba, I., Muyinga, G. A. (2011). Fire sources, disaster impacts and mitigation in Kenya secondary schools. International Journal of Disaster Management and Risk Reduction, Vol. 3. Issue 3, 2011.

[2] Allan, J. and Feare, C. J. (1996). Feral Canada geese (Branta canadensis) as a hazard to aircraft in Europe: Options for management and control. Pages 25-42 in Proceedings of 23rd Bird Strike Committee Europe Meeting. London, England.

[3] Allan, J. R. and Orosz, A. P. (2001). The costs of bird strikes to commercial aviation. Pages 218-226 in Bird Strike (2001). Proceedings of the Bird Strike Committee - USA/Canada meeting. Calgary, Alberta, Canada: Transport Canada, Ottawa, Ontario Canada.

[4] Anderson, C. and Kok, O. (1991). The crowned plover problem at airports: A simple solution. African Wildlife 45: 299-301.

[5] Archer, A. L. (2001). Potential bird and mammal strike threats. Jomo Kenyatta International Airport Nairobi - Kenya. Kenya Airports Authority.

[6] Ayres, M. (2009). Guidebook for Airport Safety Management Systems. Applied Research Associates and International Safety Research Inc. [Online]. Retrieved from www.national-academics.org/trb $(20 / 11 / 2010)$.

[7] Baum, H. (2010). Accident causes. Aviation law attorneys. [Online]. Retrieved from www.airplanecrashlawyer.com $(5 / 11 / 2010)$.

[8] Bird Hazard Risk Assessment. (2013). North West Bird Control January 2013. Produced for Cuadrilla Resources Limited in respect of safeguarding for Blackpool Airport

[9] Birger, H. \& Jeppe, N. (2005).The epistemological lifeboat.(Online).Retrieved from http://www.db.dk/ $(18 / 11 / 2010)$.

[10] Blokpoel, H. (1976). Bird hazards to aircraft problems and prevention of bird or aircraft collisions. Clarke, Irwin \& Co. Ltd./ Canadian Wildlife Service/ Publishing Centre, Supply and Services Canada. civiele luchtvaartuigen.

[11] Burger, J. (1983). Jet aircraft noise and bird strikes: why more birds are being hit. Environmental Pollution (Series A) 30:143-152.

[12] Buurma. L. S. (1996). Superabundance of birds: trends, wetlands and aviation. Pages 43-50 in Proceedings of the 23rd Bird Strike Committee Europe meeting. London, England.

[13] Carrilo, G. (2010). Introduction to disaster management. Course manual. Virtual University for Small States of the Commonwealth (VUSSC). Disaster Management 1.0 [Online]. Retrieved from www.col.org/vussc (4/11/2010).

[14] Cleary, E. (1994). An Overview of Airport Bird Management. FAA-AAS, Washington. Departement of the US Airforce.

[15] Dannatt, R. (2002), Role and Effectiveness of Government Regulation of Air Transport Safety The University of Western Australia.

[16] Devine, J. (2009). Causes of airplane accident.[Online].Retrieved from http://ezinearticles.com $(26 / 10 / 2010)$.

[17] Dolbeer, R. A. and Eschenfelder, P. (2003). Amplified bird-strike risks related to population increases of large birds in North America. Pages 49-67 in Proceedings the 26th International Bird Strike Committee meeting, Warsaw, Poland (Volume 1).

[18] GAO Report. (1995). Report to Congressional Committees, Aviation Security: The FAA Can Help Help Ensure That Airports' Access Control Systems Are Cost Effective, Report No. GAO/RCED -94-142, U.S. GPO, 1 March 1995.

[19] Garatwa, W. \& Bollin, C. (2002). Disaster risk management. A working concept. Deutsche Gesellschaft fur, O.K. KOPIE, Gmbit, Eschborn [Online]. Retrieved from www.gtz.de (26/10/2010).

[20] Godsey, O.L., (1997). Bird Aircraft Strike Hazard (BASH) Management Techniques. 
[21] Government of Kenya (GOK), 2009.National Policy on Disaster Management, Government Printers, Nairobi.

[22] Grote, A. (1994). Ecology of birds hazardous to aviation on Ysterplaat and Langebaanweg air force bases. Unpublished MSc.(Wildlife Management) dissertation. University of Pretoria.

[23] Halimu S. S, (2007). Social Services in Disaster Situations in Kenya. Les Cahiers d'Afrique de l'Est, $\mathrm{n}^{\circ}$ 35, IFRA, Nairobi, 2007

[24] Holloway, A. (2003). Rising Vulnerability, Increasing Risk. Disaster Risk Reduction

[25] ICAO (2004). Annex 14 to the convention on international civil aviation aerodromes-International standards and recommended practices, 4th ed., ICAO Vol.1. Montreal, Canada. [Online]. Retrieved from www.icao.org $(25 / 10 / 2010)$

[26] ICAO(2006) Safety Management Manual Document 9859 1st Edition, Montreal Canada

[27] Jackson C. (2001). Malindi / Watamu House Crow Control Project. Report for Watamu for the period July 2000 - February 2001. (unpublished).

[28] KCAA. (2007). Rules of the air and air traffic control regulations. Kenya Civil aviation Authority

[29] Kelly, T. C., O'Callaghan, M. J. A. and Bolger, R. (2001). The avoidance behaviour shown by the rook (Corvus frugilegus) to commercial aircraft. Pages 291-299 in H. J. Pelz, D. P. Cowan, and C. J. Feare (Editors), Advances in vertebrate pest management II. Filander Verlag.

[30] Kenya Vision 2030 Blueprint, 2009

[31] Kiema-Ngunnzi, J. (2002)."An Assessment of Recovery Strategies of the 1998 Nairobi Bomb Disaster Victims: A Case Study of the Teachers' Service Commission" Unpublished MA Project Paper, Department of Sociology, University of Nairobi.

[32] Klaver, A. (1999). Faunabeheer plan Amsterdam Airport Schiphol $2000 \mathrm{t} / \mathrm{m} 2005$.

[33] Krasner, H. (2009). The causes of aircraft accidents. Why do most planes crash, what are the most common reasons [Online]. Retrieved from www.suite101.com (4/11/2010).

[34] Kumar, U and Malik, H. (2003). Analysis of fatal human error aircraft accidents in IAF. Ind J Aerospace Med 47 (1): pp30-36.

[35] Kwiatkowski, K U, (2001). Expeditionary Air Operations in Africa: Challenges and Solutions,Fairchild Paper .Alabama: Air University Press.

[36] MacKinnon, B., (1996). New Technologies in Wildlife Control. Airport Wildlife Management Bulletin 19, Transport Canada.

[37] Mirichu, P. (2004). "Kenya Airports Rescue Plan". The Journal of Kenya Airports Authority. Vol.11 Issue 4 of April 2004.Nairobi: Kenya Airports Publication.

[38] Mokaya and Nyaga, (2009).Challenges in the Successful Implementation of Safety Management Systems in the Aviation Industry in Kenya.Paper presented at the 5th Moi University International Conference on "Research and Knowledge Dissemination towards building of Healthy and Socio-economically Stable Nations", 4th to $8^{\text {th }}$ August 2009

[39] Mokaya, S Chocho, T.A and Kosgey,D, (2009). The Performance of Aviation Regulatory System in Kenya.Paper Presented at the Moi University International Management and Entrepreneurship Conference, August 2009

[40] Mukaria, S.M (2013). Knowledge, awareness and conformity to International Airport emergency preparedness standards: the case of Wilson Airport in Nairobi, Kenya. Published Thesis. University of Nairobi.

[41] Munyi, I K., (2011).Influence of Organisational Factors on the Adoption of Safety Standards at Wilson Airport Nairobi, MBA Research Project, Moi University.

[42] Mutugi, M.W and Maingi, S.G. (2011). Disasters in Kenya.A major public health Concern.Journal of Public Health and Epidemiology, Vol. 3(1), pp.38-42, January 2011.

[43] Mutugi, M.W. and Maingi, S.G..(2011). Disasters in Kenya.A major public health Concern. Journal of Public Health and Epidemiology, Vol. 3(1), pp.38-42, January 2011.

[44] Nabutola, W, (2004). Risk and Disaster Management: A Case Study of Nairobi. Paper presented at the $3^{\text {rd }}$ FIG Regional Conference, Jakarta, Indonesia, October 3-7, 2004.

[45] National Transport Safety Board \{NTSB\}. (2003). Summary of Air Craft Accidents Dating to 1983 at or Near Hayward Airport.

[46] National Wildlife Research Centre, (1999). FAA Wildlife Strikes to Civil Aircraft in the United States. Http://lrbcg.com. United States Department of Agriculture, NWRC Ohio Field Station.

[47] Obwaya (2010). Disaster Risk Reduction Strategies in Preparedness: A case study of Jomo Kenyatta International Airport (JKIA) Nairobi Kenya. Published Thesis, University of Free State.

[48] Oladele S. F, (2005). African Air Transport in the 21st Century: A Case Study of the Contrasting Experience of Nigeria and Kenya. MSc Thesis Cranfield University. 
[49] Oladele S. F, (2005). African Air Transport in the 21st Century: A Case Study of the Contrasting Experience of Nigeria and Kenya. MSc Thesis Cranfield University.

[50] Omari R, Bosire-Ogechi E and Otike, J, (2011).Strategies for Managing Disasters in Libraries and other Information Centres.International Journal of Disaster Mnagement and Risk Reduction, Vol. 3.Issue 3, 2011.

[51] Onywere, S. (2005). The Status of Disaster Management in Kenya: The Need for Training Programmes. Paper presented to the University Network for Disaster Risk Reduction in Africa, Makerere University, Kampala 11-15 September 2005.

[52] Owen, D. (2003). Aircraft Accident Investigation. Sommerset: Hayness Publishing.

[53] Richardson, W. J., and T. West. (2000). Serious bird strike accidents to military aircraft: updated list and summary. Pages 67-98 in Proceedings of 25th International Bird Strike Committee meeting. Amsterdam, The Netherlands.

[54] Salvano, B. (2002). Gender mainstreaming in disaster reduction. International strategy for disaster reduction. [Online]. Retrieved from www.unisdr.org (15/11/2010).

[55] Senge, P. (1994). Art Kleiner; Charlot Roberts; Richard Ross and Bryan Smith The Fifth Discipline field book: Strategies And Tools For Building A Learning Organization. London: Nicholas Brealey Publishing.

[56] Stambaugh, H. (2009). An airport guide for regional emergency planning for CBRNE events. Airport cooperative research programme. Report 12, Washington. [Online]. Retrieved from www.nationalacademics.org/trb (3/11/2010).

[57] Stenman, O. (1990). Some measures used in different countries for reduction of bird strike risk around airports. Aerodrome Working Group, Fourth edition "Green Booklet". Werkgroep Preventie Vogelaanvaringen AAS/AHS. wildlife damage control workshop, Kansas City 1993 p.42-53.

[58] Suda, C. 2000. Natural disaster risk preparedness, environmental degradation and sustainable development in Kenya. Institute of African Studies. African study monograph, 21 (3) 91-103

[59] Swabrick, N. (2009). Air crashes, causes and consequences. Te-Ara encyclopedia of New Zealand, [Online]. Retrieved from www.teara.govt.nz/en/air-crashes (26/10/2010). 